This item was submitted to Loughborough's Research Repository by the author.

Items in Figshare are protected by copyright, with all rights reserved, unless otherwise indicated.

\title{
Computational fluid dynamics (CFD) modeling of removal of contaminants of emerging concern in solar photo-Fenton raceway pond reactors
}

\section{PLEASE CITE THE PUBLISHED VERSION}

https://doi.org/10.1016/j.cej.2020.127392

\section{PUBLISHER}

Elsevier

VERSION

AM (Accepted Manuscript)

\section{PUBLISHER STATEMENT}

This paper was accepted for publication in the journal Chemical Engineering Journal and the definitive published version is available at https://doi.org/10.1016/j.cej.2020.127392.

LICENCE

CC BY-NC-ND 4.0

\section{REPOSITORY RECORD}

Peralta-Muniz-Moreira, Rodrigo, Alejandro Cabrera Reina, Paula Soriano Molina, Jose Antonio Sánchez Pérez, and Gianluca Li-Puma. 2020. "Computational Fluid Dynamics (CFD) Modeling of Removal of Contaminants of Emerging Concern in Solar Photo-fenton Raceway Pond Reactors". Loughborough University. https://hdl.handle.net/2134/13293179.v1. 


\title{
Computational Fluid Dynamics (CFD) Modeling of Removal of Contaminants of Emerging Concern in Solar Photo-Fenton Raceway Pond Reactors
}

Rodrigo Peralta Muniz Moreira ${ }^{\mathrm{a},{ }^{*}}$, Alejandro Cabrera Reina ${ }^{\mathrm{b}}$, Paula Soriano Molina ${ }^{\mathrm{c}, \mathrm{d}}$ Jose Antonio Sánchez Pérez ${ }^{\mathrm{c}, \mathrm{d}}$, Gianluca Li Puma ${ }^{\mathrm{a}, *}$

aEnvironmental Nanocatalysis \& Photoreaction Engineering, Department of Chemical Engineering, Loughborough University, Loughborough, United Kingdom.

bPrograma Institucional de Fomento a la Investigación, Desarrollo e Innovación (PIDi), Universidad Tecnológica Metropolitana, Santiago, Chile

'Solar Energy Research Centre (CIESOL), Joint Centre University of Almería-CIEMAT, Carretera de Sacramento s/n, E-04120, Almería, Spain.

${ }^{\mathrm{d} C h e m i c a l ~ E n g i n e e r i n g ~ D e p a r t m e n t, ~ U n i v e r s i t y ~ o f ~ A l m e r i ́ a, ~ C t r a ~ d e ~ S a c r a m e n t o ~ s / n, ~ E-04120, ~}$ Almería, Spain.

*Corresponding authors: Rodrigo PERALTA MUNIZ MOREIRA (r.peralta-munizmoreira@lboro.ac.uk) and Gianluca LI PUMA (g.lipuma@lboro.ac.uk)

\begin{abstract}
The impact of mixing and hydrodynamics on the removal of contaminants of emerging concern (CECs) detected in a secondary WWTP effluent by the solar photo-Fenton process in a pilot scale Raceway Pond Reactor (RPR) was investigated by computational fluid dynamics (CFD). The CFD model incorporated the solar photo-Fenton CECs oxidation kinetics at neutral $\mathrm{pH}$ with $\mathrm{Fe}^{3+}$-EDDS, the radiation transport through the water, and the turbulent flow field produced by a paddle wheel mixer. The fluid dynamics was solved by a transient-multiphase flow model (Volume of Fluid with Sliding Mesh Model) and by a steady-state momentum
\end{abstract}


source domain (SD) model. Experimental RPR mixing time and CECs removal under transient conditions validated the models. The computationally faster SD model predicted the CECs removal varying the paddle wheel rotational speed, the solar irradiance, and fluid residence time. Deviations from an ideal CSTR were significative $(>10 \%)$ when the CECs halflife/mixing time ratios were $<1$, while residence time had minor influence. The mixing effects were amplified in a scaled-up RPR and treatment capacity decreased $10 \%$ compared with a CSTR. Overall, this study reveals that the design of hydrodynamics in large-scale RPRs must be carefully examined to reduce power consumption while increasing mixing performance.

Keywords: Advanced oxidation process; water pollutants; solar reactor; modeling, scale-up.

\section{Introduction}

Many water challenges need to be addressed in the near future. Water scarcity favored by climate change and increasing water demand require the protection and sustainable management of the existing hydric resources. In this context, the adequate treatment of wastewaters is a crucial factor. The widely adopted conventional activated sludge process in municipal wastewater treatment plants (WWTPs) is simple, robust and highly efficient in the degradation of organic matter and nutrients under reasonable costs [1]. However, it is also wellknown that most WWTP effluents still contain hundreds of organic pollutants at concentrations

in the range from $\mu \mathrm{g} / \mathrm{L}$ to $\mathrm{ng} / \mathrm{L}[2,3]$. These compounds, known as contaminants of emerging concern (CECs), have an impact to the environment through their associated hazardous effects, such as endocrine disruption [4] or generation of antibiotic resistance bacteria [5] among others, and the interconnection of rivers, seas, oceans, makes this a global problem [6].

Considering the unavoidable global presence of CECs, there is an increasing trend in implementing effective tertiary treatments in WWTPs, which are able to prevent the release of 
these compounds to the aquatic ennvironment. Among these, advanced oxidation processes (AOPs) have been successfully applied to remove CECs from WWTP effluents, and the solar photo-Fenton treatment is one of the most promising sustainable process. In the last years, the competitiveness of the solar photo-Fenton process has significantly gained importance. The use of iron complexing agents that work at neutral $\mathrm{pH}$ represents a key progress, since avoids the acidification step needed to keep the iron in solution during the treatment and the subsequent neutralization step [7], although it can also have negative impact on the operating costs [8]. Many iron chelating agents have been investigated including oxalate [9], citrate [10], ethylenediamine-N,N'-disuccinic acid (EDDS) [11], nitrilotriacetic acid (NTA) [12], diethylene triamine pentaacetic acid (DTPA) [13] or ethylenediamine-N, N'-bis acid (EDDHA) [14]. Among these, EDDS has shown the most promising results $[15,16,17]$.

On the other hand, one of the most important drawbacks of solar photo-Fenton is the unfeasibility of treating large amounts of wastewater due to the type of photoreactors that are traditionally employed in solar photocatalytic applications (e.g., the Compound Parabolic Collectors, CPCs). In this context, Raceway Pond Reactors (RPRs), normally used for largescale algae cultivation under solar radiation, have arisen as a low-cost scalable option for use in solar photo-Fenton treatment of CECs [18]. Recently published studies have demonstrated their higher treatment capacity, operation flexibility and lower investment costs in comparison to CPCs $[19,20]$, as well as the feasibility for working in continuous flow mode $[8,21]$.

In a RPR, a pond is divided into channels and water is set in motion and mixed by means of a paddle wheel. Although studies related to fluid dynamics of RPRs have been published to date, all of them have focused on microalgae production, which is normally produced under laminar flow conditions [22, 23, 24]. It should be noted that microalgae production presents significant differences on the time-scales with respect to the solar photoFenton, in which the removal of CECs can be expected to occur in only tens of minutes and 
the distribution of the generated short-life oxidizing species in the reactor is especially critical for process performance. Moreover, solar photo-Fenton RPRs are normally operated under turbulent flow.

In this study, the impact of mixing and hydrodynamics on the removal of contaminants of emerging concern (CECs) detected in a secondary WWTP effluent by the solar photo-Fenton process in a pilot scale RPR was investigated by computational fluid dynamics (CFD). One objective was to provide an accurate model of the fluid flow in the RPR while reducing the computational time. For this purpose, the fluid dynamics was solved by a transient-multiphase flow model (Volume of Fluid with Sliding Mesh Model) and by a steady-state momentum source domain (SD) model. Another objective was to validate and incorporate in the CFD model the solar photo-Fenton CECs oxidation kinetics, the radiation transport through the water, and the turbulent flow field produced by a paddle wheel mixer to unveil the impact of the paddle wheel rotational speed, the fluid residence time $\left(\theta_{\text {res }}\right)$ and the solar radiation conditions on the treatment efficiency of pilot-scale and scaled-up RPRs. The validated model developed in this study can be further used for design and optimization of large-scale RPR reactors mitigating potential mixing flaws.

\section{Methodology}

\subsection{Reactor geometry, operating conditions and experimental data}

The removal of the three most abundant CECs detected in a secondary effluent collected from El Toyo WWTP (Almería, Spain) (O-desmethyltramadol (O-DSMT), $O$ desmethylvenlafaxine (O-DSMV) and gabapentin (GBP)) [19] by the solar photo-Fenton process at neutral $\mathrm{pH}$ was investigated in a pilot-scale Raceway Pond Reactor (RPR) installed at the Solar Energy Research Center (CIESOL) at the University of Almeria (Andalusia, Spain) $[17,19]$. The RPR was a $5 \mathrm{~cm}$ deep pond divided into two channels interconnected by $180^{\circ}$ 
bends with flow deflectors, producing a closed circuit. The fluid in the RPR was moved by a paddle wheel at rotational speeds ranging from 11 to $44 \mathrm{rpm}$, providing mixing in the reactor. The RPR was operated in continuous flow-through mode (single pass) with fluid residence times varying from 5 to 25 minutes. The experiments used to validate the model results were conducted as follows: the RPR was initially loaded with the WWTP secondary effluent, next the reagents were added to the reactor and for the first 30 min the RPR was operated in batch mode to totally convert the $\mathrm{Fe}^{3+}$-EDDS. Subsequently, the wastewater feed pump and the reagent supply pumps were switched on, and the reactor was operated in continuous mode (single pass). The hydraulic residence time was varied by adjusting the flow rate of the feed pumps. More details are reported elsewhere [19]. An illustration of the RPR showing the paddle wheel location and the positions of the inlet and outlet streams is shown in Fig. S1, in Supplementary Information (SI).

The concentration of $\mathrm{H}_{2} \mathrm{O}_{2}$ and $\mathrm{Fe}^{3+}$-EDDS (at $\mathrm{Fe}^{3+}$-EDDS molar ratio of 1:1) were 0.88 $\mathrm{mM}(30 \mathrm{mg} / \mathrm{L})$ and $0.1 \mathrm{mM}(5.6 \mathrm{mg} / \mathrm{L})$, respectively, which match the values commonly used for the removal CEC in RPRs by the photo-Fenton process [20]. The concentrations of total inorganic carbon (TIC) and total organic carbon (TOC) in the WWTP effluent were $1.275 \mathrm{mM}$ and $0.908 \mathrm{mM}$, respectively, determined using a Shimadzu-V $\mathrm{V}_{\mathrm{CHP}}$ TOC analyzer fitted with an autosampler system. The intensity of the incident used for modeling purposes was assumed to be constant over the UVA spectrum (327-384 nm) and was varied from 10 to $30 \mathrm{~W} / \mathrm{m}^{2}$. The incidence angle of the solar radiation was considered to be normal to the free surface (global radiation emitted only as direct radiation). These assumptions can reduce the computational cost of the model, while maintaining accurate solutions of the radiation field in the liquid solution [25]. The RPR geometry, operating conditions, physical properties and optical properties are summarized in Table 1. 
Experimental data used for model validation were taken from [19], except for the experiments performed to determine the mixing time in the RPR. The mixing time in the RPR was computed by a pulse response analysis. A $1 \mathrm{~mL}$ pulse of $\mathrm{H}_{2} \mathrm{SO}_{4}(98 \%)$ tracer was injected at the center of the RPR, $135 \mathrm{~mm}$ downstream from the paddlewheel, and the $\mathrm{pH}$ was monitored (Hannah Instruments HI98190) at three different positions (see Fig. S2 (SI)) until the relative difference between these three points fell below $5 \%$ of the steady state $\mathrm{pH}$ value. The $\mathrm{pH}$ response time was significantly faster than the mixing time in the reactor, thus it was neglected.

Table 1. (a) Reactor geometry, (b) operating conditions, (c) concentrations of chemical species in the WWTP effluent, (d) physical properties and (e) optical properties of the catalyst.

\begin{tabular}{|c|c|}
\hline (a) Reactor geometry & \\
\hline Area $(\boldsymbol{A})\left[\mathrm{m}^{2}\right]$ & 0.330 \\
\hline Length $\left(\boldsymbol{L}_{\text {reactor }}\right)\left[\mathrm{m}^{2}\right]$ & 0.988 \\
\hline Width $\left(\boldsymbol{W}_{\text {reactor }}\right)[\mathrm{m}]$ & 0.187 \\
\hline Bend radius $\left(\boldsymbol{R}_{\text {bend }}\right)[\mathrm{m}]$ & 0.190 \\
\hline Deflector radius $\left(\boldsymbol{R}_{\text {deflector }}\right)[\mathrm{m}]$ & 0.092 \\
\hline Liquid depth $(\boldsymbol{d})[\mathrm{m}]$ & 0.05 \\
\hline Volume $\left(\boldsymbol{V}_{\boldsymbol{R}}\right)\left[\mathrm{m}^{3}\right]$ & 0.019 \\
\hline Paddle wheel width $\left(\boldsymbol{W}_{\text {paddle-wheel }}\right)[\mathrm{m}]$ & 0.181 \\
\hline Paddle wheel radius $\left(\boldsymbol{r}_{\text {paddle-wheel }}\right)[\mathrm{m}]$ & 0.10 \\
\hline Distance between the paddle axis and bottom of the RPR $\left(\boldsymbol{L}_{\text {axis }}\right)[\mathrm{m}]$ & 0.103 \\
\hline Number of blades of the paddle wheel & 4 \\
\hline (b) Operating conditions & \\
\hline Irradiance $\left(\boldsymbol{E}_{\boldsymbol{p}, \boldsymbol{o}}\right)$ at UVA spectrum [W] & $10.0,20.0,30.0$ \\
\hline Rotational speed of the paddle wheel $(\boldsymbol{N})[\mathrm{rpm}]$ & $11.0,22.0,33.0,44.0$ \\
\hline Residence time $\left(\boldsymbol{\theta}_{\text {res }}\right)$ [min] & $5.0-25.0$ \\
\hline (c) Concentration of chemical species in the WWTP effluent & \\
\hline$\left[\mathrm{H}_{2} \mathrm{O}_{2}\right][\mathrm{M}]$ & $8.8 \cdot 10^{-4}$ \\
\hline$\left[\mathrm{Fe}^{3+}-\mathrm{EDDS}\right][\mathrm{M}]$ & $1.0 \cdot 10^{-4}$ \\
\hline$[\mathrm{IC}][\mathrm{M}]$ & $1.275 \cdot 10^{-3}$ \\
\hline$[\mathrm{OM}][\mathrm{M}]$ & $9.083 \cdot 10^{-4}$ \\
\hline [O-DSMT] [M] & $4.01 \cdot 10^{-9}$ \\
\hline [O-DSMV] [M] & $9.11 \cdot 10^{-9}$ \\
\hline$[\mathrm{GBP}][\mathrm{M}]$ & $2.34 \cdot 10^{-9}$ \\
\hline (d) Physical properties & \\
\hline Density $(\boldsymbol{\rho})\left[\mathrm{kg} \mathrm{m}^{-3}\right]$ & 998.2 \\
\hline Viscosity $(\boldsymbol{\mu})[\mathrm{cP}]$ & 1.003 \\
\hline
\end{tabular}




\begin{tabular}{|c|c|}
\hline 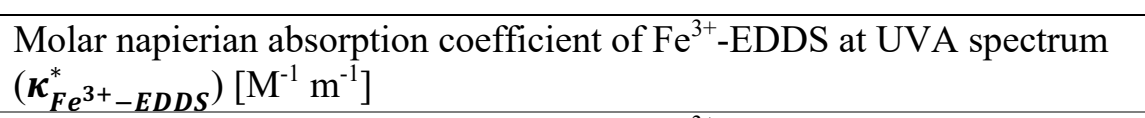 & 248750 \\
\hline $\begin{array}{l}\text { Molar napierian absorption coefficient of } \mathrm{Fe}^{3+}-\mathrm{EDDS}_{\mathrm{ox}} \text { at UVA spectrum } \\
\left(\boldsymbol{\kappa}_{\boldsymbol{F} \boldsymbol{e}^{3+}-\boldsymbol{E} \boldsymbol{D} \boldsymbol{D} \boldsymbol{S}_{\boldsymbol{o x}}}^{*}\left[\mathrm{M}^{-1} \mathrm{~m}^{-1}\right]\right.\end{array}$ & 201308 \\
\hline
\end{tabular}

\subsection{Mathematical model}

The CFD modeling of the paddle wheel motion yields a multiphase flow (water and air) and a transient solution, as those typically found in open channels [26, 27]. However, when this is coupled with the reacting flow model of the solar photo-Fenton process in the RPR, the computational time of the simulations reaches impracticable levels, given that the timescales of the flow structures are in the order of microseconds (at least 20 times lower than the period of the paddle wheel rotation), whereas the timescales of the chemical reactions are in the order of few minutes. Thus, a new methodology based on a source of momentum was proposed in this study to compute the flow as a single-phase and at steady state.

\subsubsection{Mass and momentum conservation}

The fluid flow was modeled as turbulent $(R e \sim 5000$, flow is turbulent when $R e>500$ in open channels) using the Reynolds-Averaged Navier-Stokes (RANS) approach. The mass and momentum conservation equations for incompressible flow written using the cartesian index notation are:

$$
\begin{aligned}
& \frac{\partial \rho}{\partial t}+\frac{\partial}{\partial x_{i}}\left(\rho u_{i}\right)=0 \\
& \frac{\partial}{\partial t}\left(\rho u_{i}\right)+\frac{\partial}{\partial x_{j}}\left(\rho u_{j} u_{i}\right)=-\frac{\partial p}{\partial x_{i}}+\tau_{j i}^{e f f}+\rho g_{i}+S_{m, i}
\end{aligned}
$$

where the velocity, $u_{i}$, the pressure, $p$, and the density, $\rho$, are time-averaged fields, $g_{i}$ is the gravity vector, $S_{m, i}$ is a user-defined momentum source. The effective stress tensor, $\tau_{j i}^{e f f}$, is defined as: 


$$
\tau_{j i}^{e f f}=\tau_{j i}+\tau_{j i}^{t}
$$

where the viscous stress tensor, $\tau_{j i}$, for a Newtonian fluid is given by

$$
\tau_{j i}=\mu\left(\frac{\partial u_{i}}{\partial x_{j}}+\frac{\partial u_{j}}{\partial x_{i}}-\frac{2}{3} \delta_{j i} \frac{\partial u_{k}}{\partial x_{k}}\right)
$$

and the Reynolds stress tensor, $\tau_{j i}^{t}$, assuming the Boussinesq approximation, is defined as

$$
\tau_{j i}^{t}=\mu_{t}\left(\frac{\partial u_{i}}{\partial x_{j}}+\frac{\partial u_{j}}{\partial x_{i}}\right)-\frac{2}{3}\left(\rho k+\mu_{t} \frac{\partial u_{k}}{\partial x_{k}}\right) \delta_{j i}
$$

where $\mu_{t}$ is the turbulent viscosity and $k$ is the turbulent kinetic energy.

The Shear Stress Transport (SST) k- $\omega$ model [28] was used to compute the turbulent viscosity by solving additional transport equations for the turbulent kinetic energy ( $k$, in Eq. (6), and for the specific dissipation rate ( $\omega$, in Eq. (7)).

$$
\begin{aligned}
& \frac{\partial}{\partial t}(\rho k)+\frac{\partial}{\partial x_{j}}\left(\rho k u_{j}\right)=\frac{\partial}{\partial x_{j}}\left[\left(\mu+\frac{\mu_{t}}{\sigma_{k}}\right) \frac{\partial k}{\partial x_{j}}\right]+G_{k}-D_{k}+G_{b}+S_{k} \\
& \frac{\partial}{\partial t}(\rho \omega)+\frac{\partial}{\partial x_{j}}\left(\rho \omega u_{j}\right)=\frac{\partial}{\partial x_{j}}\left[\left(\mu+\frac{\mu_{t}}{\sigma_{\omega}}\right) \frac{\partial \omega}{\partial x_{j}}\right]+G_{\omega}-D_{\omega}+G_{\omega b}+S_{\omega}
\end{aligned}
$$

In these equations, $G_{k}$ is the generation of turbulent kinetic energy due to mean velocity gradients, $G_{\omega}$ is the generation of $\omega, \sigma_{k}$ and $\sigma_{\omega}$ are the turbulent Prandtl numbers for $k$ and $\omega$, respectively, $D_{k}$ and $D_{\omega}$ represent the dissipation of $k$ and $\omega$ due to turbulence, $G_{b}$ and $G_{\omega b}$ are the buoyance terms, and $S_{k}$ and $S_{\omega}$ are user-defined source terms. The turbulent viscosity in SST model is computed by:

$$
\mu_{t}=\alpha^{*} \frac{\rho k}{\omega}
$$

where $\alpha^{*}$ is a function that depends on the distance from the wall. Further details of the SST model implementation and the definitions of the model parameters can be found elsewhere [29]. 


\subsubsection{1. $\quad$ Source domain (SD) model}

The Source Domain (SD) model, adapted from the Actuator Disk Theory [30], is here proposed to solve the flow in the RPR under steady state conditions. In this method, the geometry of the paddle wheel was removed from the numerical domain, and the motion of the paddle wheel was modeled numerically using user-defined and time-averaged sources of momentum and turbulent kinetic energy. The sources on the mentioned equations were applied in a separated domain in the RPR at the location of the paddle wheel (total length of the domain, $L_{s-d}$, of $216 \mathrm{~mm}$ ), herein named as the source domain. A scheme of the Actuator Disk Theory is illustrated in Fig. S3, SI.

The source of momentum was calculated by assuming the paddlewheel thrust force aligned with the flow direction $(+z)$ and with the drag force applied in the opposite direction $(-z)$. The thrust and drag forces were calculated with the paddlewheel surface perpendicular to the direction fluid flow and with the force applied on the area of the paddle immersed into the fluid. The net force in the axial flow direction, $z$, was computed by [30]:

$$
F_{\text {Net }}=\frac{1}{2} \rho A_{\text {paddle-wheel }} C_{T}\left(N r_{t}\right)-\frac{1}{2} \rho A_{\text {paddle-wheel }} C_{D}\left(u_{z}-N r_{t}\right)\left|u_{z}-N r_{t}\right|
$$

where $A_{\text {paddle-wheel }}$ is the area of the paddle immersed in the liquid, $C_{T}$ is the thrust coefficient, $C_{D}$ is the drag coefficient, $u_{z}$ is the local velocity-z, $N$ is the rotational speed and $r_{t}$ is the mean radius of the paddle wheel calculated by:

$$
r_{t}=r_{\text {paddle }}-\frac{d}{2}
$$

The coefficients $C_{T}$ and $C_{D}$ were defined as $C_{T}=2$ and $C_{D}=10$. These were calculated by matching the pumping flow rate $\left(Q_{p}\right)$ and the pressure gradient, $\Delta p$ using the SD model with those from CFD simulations using a transient and multiphase flow solution (Volume of Fluid model, VOF, and Sliding Mesh, SM) in the RPR. The SD model results calculated using $C_{T}=$ 
2 and $C_{D}=10$ constants deviated from the $\mathrm{VOF} / \mathrm{SM}$ by $2.4 \%$ and $11 \%$ for the $Q_{p}$ and $\Delta p$, respectively (results shown in Table S1, SI).

The momentum source was implemented assuming a Gaussian distribution of the resulting force along the $\mathrm{z}^{\text {th }}$ direction. Then, the maximum value of momentum source was applied at the position of the paddle wheel axis $\left(z_{0}\right)$, while the limits of the domain received the least value. The standard deviation of the Gaussian distribution $(\sigma)$ was assumed as equal to $L_{s-d} / 6$, which implies that $99.7 \%$ of the momentum source is within the source domain. The momentum source is defined as the net force per volume, and is given by:

$$
S_{m, z}=\frac{1}{\sqrt{2 \pi \sigma^{2}}} e^{-\left(\frac{z-z_{0}}{2 \sigma^{2}}\right)} \frac{F_{\text {Net }}}{W_{\text {reactor }} d}
$$

In addition to the conceptual use of the momentum source, this region must also account for the increase on turbulent kinetic energy, since the main driving force of micro-mixing is the turbulent diffusion. The approach proposed to model the source of turbulent kinetic energy $(\Delta k)$ was adapted from literature [31]. The $\Delta k$ was calibrated through numerical measurements of the increase on the turbulence intensity at the paddle wheel, $\Delta I_{T}$, obtained from CFD simulations using the VOF/SM model. By assuming a fixed increment on the turbulence intensity $\left(\Delta I_{T}=0.05\right)$, the $\Delta k$ was calculated by:

$$
\Delta k=\frac{3}{2} \Delta I_{T} u_{i}^{2}
$$

Then, assuming a Gaussian distribution in the source domain along the $\mathrm{z}^{\text {th }}$ direction, the source of turbulent kinetic energy can be calculated by:

$$
S_{k}=\frac{1}{\sqrt{2 \pi \sigma^{2}}} e^{-\left(\frac{z-z_{0}}{2 \sigma^{2}}\right)} \rho \Delta k N r_{t}
$$




\subsubsection{2. $\quad$ Sliding mesh and VOF (VOF/SM) model}

The VOF and Sliding Mesh model (VOF/SM) simulations were performed to compare and validate the SD method. In the SM approach, the geometry of the paddle wheel moves rigidly in a given dynamic mesh zone, while the cells at the interface between the moving and stationary zones are connected by non-conformal interfaces. Fig. S4 (SI) shows the geometry used in this model and the interfaces between the moving and stationary domains.

Since the movement of the paddle wheel is directly accounted for in this model, the simulation using the SM leads to an intrinsic transient and multiphase flow pattern. The VOF model was then used to track the interface between the liquid solution and air throughout the domain. The VOF model assumes that both phases (water and air) share the same velocity field, and the momentum equation (Eq. (2)) is dependent on the volume fractions of the phases through the mixture properties:

$$
\begin{aligned}
& \rho=\left(1-\alpha_{g}\right) \rho_{l}+\alpha_{g} \rho_{g} \\
& \mu=\left(1-\alpha_{g}\right) \mu_{l}+\alpha_{g} \mu_{g}
\end{aligned}
$$

where the indexes $l$ and $g$ stand for liquid and gas properties, and $\alpha_{g}$ is the volume fraction of the gas phase.

The tracking of the interface between the phases was accomplished by the solution of a continuity equation for the volume fraction of the secondary phase, which was selected to be the air. This equation has the following form:

$$
\frac{\partial}{\partial t}\left(\alpha_{g} \rho_{g}\right)+\frac{\partial}{\partial x_{j}}\left(\alpha_{g} \rho_{g} u_{j}\right)=0
$$

\subsubsection{Species transport modeling}

The mass conservation of the $k^{\text {th }}$ chemical species for turbulent flows using the Reynolds' analogy hypothesis can be obtained through the solution of Eq. (16-17): 


$$
\begin{aligned}
& \frac{\partial}{\partial t}\left(\rho Y_{k}\right)+\frac{\partial}{\partial x_{j}}\left(\rho u_{j} Y_{k}\right)=\frac{\partial}{\partial x_{j}}\left[\left(\rho D_{k, m}+\frac{\mu_{t}}{S c_{t}}\right) \frac{\partial Y_{k}}{\partial x_{j}}\right]+M_{w, k} \sum_{l=1}^{N_{r}}\left(v_{k, l}^{\prime \prime}-v_{k, l}^{\prime}\right) r_{l} \\
& Y_{N}=1-\sum_{k}^{N_{s}-1} Y_{k}
\end{aligned}
$$

where $Y_{k}$ is the mass fraction of the $k$ specie, $D_{k, m}$ is the mass diffusivity of specie $k$ in the mixture and $M_{w, k}$ is the molecular weight of specie $k$. The $v_{k, l}^{\prime}$ and $v_{k, l}^{\prime \prime}$ are the stoichiometric coefficient for reactant $k$ in reaction $l$ and the stoichiometric coefficient for product $k$ in reaction $l$, and $r_{l}$ is the reaction rate for the reaction $l$ given in $\left[\mathrm{mol} \mathrm{m}^{-3} \mathrm{~s}^{-1}\right]$ (kinetic mechanism is shown in Section 2.2.3). $N_{r}$ is the total number of chemical reactions and $N_{s}$ is the total number of chemical species present in the system. The physical properties were assumed independent of the species concentration (diluted mixture). The turbulent Schmidt number $\left(S c_{t}\right)$ number was defined as 0.7 , the most common value used to compute the turbulent mass diffusion in mixing studies [32].

Since under turbulent flows the turbulent diffusion term controls the micro-mixing $\left(\mu_{t} / S c_{t} \gg \rho D_{k, m}\right)$, the laminar diffusivity of all chemical species in the mixture was insignificant and therefore it was fixed as $D_{k, m}=1 \cdot 10^{-9} \mathrm{~m}^{2} / \mathrm{s}$. Moreover, the effects of turbulent fluctuations on the kinetics rates were neglected, since the timescales of the chemical reactions are much higher than the turbulent mixing timescales $(1 / \omega)$.

\subsubsection{Kinetic mechanism}

The solar photo-Fenton kinetic mechanism (Table 2) was adapted from a previous study of removal of O-DSMT, O-DSMV and GBP from WWTP effluents in a RPR under batch operation [19]. The number of elementary reactions were reduced from 18 to 14 , to reduce the overall CFD computational time, by assuming steady-state equilibrium of the concentrations of $\mathrm{OH}, \mathrm{Fe}^{3+}$-EDDS and $\mathrm{Fe}^{3+}-\mathrm{EDDS}_{\text {ox }}$. 
Table 2. Chemical reaction mechanism of the solar photo-Fenton process at neutral $\mathrm{pH}$.

\begin{tabular}{|c|c|c|c|}
\hline \multicolumn{2}{|c|}{ Reaction } & \multirow{2}{*}{ 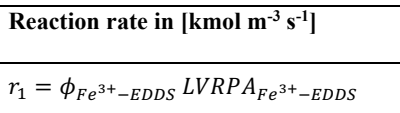 } & \multirow{2}{*}{$\begin{array}{l}\text { Kinetic constant } \\
\phi_{F e^{3+}-E D D S}=9.62 \cdot 10^{-1}\left[\mathrm{~mol} \mathrm{E}^{-1}\right]\end{array}$} \\
\hline $\mathrm{R}_{1}$ & $F e^{3+}-E D D S+h v \stackrel{\phi_{F e^{3+}-E D D S}}{\longrightarrow} F e^{2+}-E D D S+H^{+}$ & & \\
\hline $\mathrm{R}_{2}$ & $\mathrm{Fe}^{2+}-\mathrm{EDDS}+\mathrm{H}_{2} \mathrm{O}_{2} \stackrel{k_{2}}{\rightarrow} \mathrm{Fe}^{3+}-\mathrm{EDDS}+\mathrm{OH}+\mathrm{OH}^{-}$ & $r_{2}=k_{2}\left[F e^{2+}-E D D S\right]\left[H_{2} O_{2}\right]$ & $k_{2}=28333.33\left[\mathrm{M}^{-1} \mathrm{~s}^{-1}\right]$ \\
\hline $\mathrm{R}_{3}$ & $\mathrm{Fe}^{2+}-\mathrm{EDDS}^{k_{3}} \rightarrow \mathrm{Fe}^{2+}+\mathrm{EDDS}^{\cdot 3-}$ & $r_{3}=k_{3}\left[F e^{2+}-E D D S\right]$ & $k_{3}=9.88 \cdot 10^{-1}\left[\mathrm{~s}^{-1}\right]$ \\
\hline $\mathrm{R}_{4}$ & $\mathrm{Fe}^{2+}+\mathrm{H}_{2} \mathrm{O}_{2} \stackrel{k_{4}}{\rightarrow} \mathrm{Fe}(\mathrm{OH})_{3}+\mathrm{OH}^{-}+\mathrm{OH}^{-}$ & $r_{4}=k_{4}\left[F e^{2+}\right]\left[H_{2} O_{2}\right]$ & $k_{4}=76.00\left[\mathrm{M}^{-1} \mathrm{~s}^{-1}\right]$ \\
\hline $\mathrm{R}_{5}$ & $\mathrm{Fe}^{3+}-\mathrm{EDDS}+\mathrm{H}_{2} \mathrm{O}_{2} \stackrel{k_{5}}{\rightarrow} \mathrm{Fe}^{2+}-E D D S+\mathrm{O}_{2}^{-}+2 \mathrm{H}^{+}$ & $r_{5}=k_{5}\left[F e^{3+}-E D D S\right]\left[H_{2} O_{2}\right]$ & $k_{5}=2.33\left[\mathrm{M}^{-1} \mathrm{~s}^{-1}\right]$ \\
\hline $\mathrm{R}_{6}$ & $F e^{3+}-E D D S+O H \stackrel{k_{6}}{\rightarrow} F e^{3+}-E D D S_{o x}$ & $r_{6}=k_{6}\left[\mathrm{Fe}^{3+}-E D D S\right]\left[O \mathrm{H}^{\cdot}\right]$ & $k_{6}=6.50 \cdot 10^{8}\left[\mathrm{M}^{-1} \mathrm{~s}^{-1}\right]$ \\
\hline $\mathrm{R}_{7}$ & $F e^{3+}-E D D S_{o x}+h v \stackrel{\phi_{F e^{3+-E D D S}}}{\longrightarrow} \mathrm{Fe}^{2+}+E D D S^{3-}$ & $r_{7}=\phi_{F e^{3+}-E D D S_{o x}} L V R P A_{F e^{3+}-E D D S_{o x}}$ & $\phi_{F e^{3+}-E D D S_{o x}}=1.56 \cdot 10^{-1}\left[\mathrm{~mol} \mathrm{E}^{-1}\right]$ \\
\hline $\mathrm{R}_{8}$ & $I C+O H \cdot \stackrel{k_{8}}{\rightarrow} I C X$ & $r_{8}=k_{8}[I C][O H \cdot]$ & $k_{8}=8.50 \cdot 10^{6}\left[\mathrm{M}^{-1} \mathrm{~s}^{-1}\right]$ \\
\hline $\mathrm{R}_{9}$ & $O M+O H \cdot \stackrel{k_{9}}{\rightarrow} M X$ & $r_{9}=k_{9}[O M][O H \cdot]$ & $k_{9}=6.5 \cdot 10^{7}\left[\mathrm{M}^{-1} \mathrm{~s}^{-1}\right]$ \\
\hline $\mathrm{R}_{10}$ & $\mathrm{H}_{2} \mathrm{O}_{2}+\mathrm{OH} \cdot \stackrel{k_{10}}{\rightarrow} 2 \mathrm{H}_{2} \mathrm{O}+\mathrm{O}_{2}$ & $r_{10}=k_{10}\left[\mathrm{H}_{2} \mathrm{O}_{2}\right][\mathrm{OH} \cdot]$ & $k_{10}=2.67 \cdot 10^{7}\left[\mathrm{M}^{-1} \mathrm{~s}^{-1}\right]$ \\
\hline $\mathrm{R}_{11}$ & $\operatorname{EDDS}^{\cdot 3-}+\mathrm{H}_{2} \mathrm{O}_{2} \stackrel{k_{11}}{\rightarrow} 10 M X$ & $r_{11}=k_{11}\left[E D D S^{\cdot 3-}\right]\left[H_{2} O_{2}\right]$ & $k_{11}=3.67 \cdot 10^{7}\left[\mathrm{M}^{-1} \mathrm{~s}^{-1}\right]$ \\
\hline $\mathrm{R}_{12}$ & $O-D S M T+O H \stackrel{k_{12}}{\rightarrow} 15 M X$ & $r_{12}=k_{12}[O-D S M T][O H \cdot]$ & $k_{12}=1.47 \cdot 10^{9}\left[\mathrm{M}^{-1} \mathrm{~s}^{-1}\right]$ \\
\hline $\mathrm{R}_{13}$ & $O-D S M V+O H \cdot \stackrel{k_{13}}{\rightarrow} 16 M X$ & $r_{13}=k_{13}[O-D S M V][O H \cdot]$ & $k_{13}=1.31 \cdot 10^{9}\left[\mathrm{M}^{-1} \mathrm{~s}^{-1}\right]$ \\
\hline $\mathrm{R}_{14}$ & $G B P+O H \stackrel{k_{14}}{\rightarrow} 9 M X$ & $r_{14}=k_{14}[G B P][O H \cdot]$ & $k_{14}=8.50 \cdot 10^{8}\left[\mathrm{M}^{-1} \mathrm{~s}^{-1}\right]$ \\
\hline
\end{tabular}

Assuming very fast reactions of the $\mathrm{OH}^{\cdot}\left(d\left[\mathrm{OH}^{\cdot}\right] / d t=0\right)$, the $\left[\mathrm{OH}^{\cdot}\right]$ can be calculated by Eq. (18). The quantum yields, $\phi_{F e^{3+}-E D D S}$ and $\phi_{F e^{3+}-E D D S_{O x}}$ in $\mathrm{R}_{1}$ and $\mathrm{R}_{7}$, respectively, were calculated by the ratio between the forward kinetic constant and the sum of forward and backward kinetics constants of the photo-chemical reactions in the detailed mechanism [17]. The validation of the kinetics assumptions in a RPR modeled as a perfectly mixed tank reactor (Fig. S5, SI) shows insignificant differences between the 18 and the 14 elementary reaction kinetic mechanisms.

$$
[O H]_{S S}=\frac{k_{2}\left[F e^{2+}-E D D S\right]\left[H_{2} O_{2}\right]+k_{4}\left[F e^{2+}\right]\left[H_{2} O_{2}\right]}{k_{5}\left[F^{3+}-E D D S\right]+k_{8}[I C]+k_{9}[O M]+k_{10}\left[H_{2} O_{2}\right]+k_{12}[O-D S M T]+k_{13}[O-D S M V]+k_{14}[G B P]}
$$




\subsubsection{Radiation transport modeling}

The Radiation Transport Equation (RTE) was solved to compute the local volumetric rate of photon absorption (LVRPA) of the catalyst iron complex ( $\left.L V R P A_{F e^{3+}-E D D S}\right)$ and of the oxidized catalyst iron complex $\left(L V R P A_{F e^{3+}-E D D S_{o x}}\right)$. Neglecting the fluid medium radiation scattering and emission, the RTE yields:

$$
\frac{d I(\boldsymbol{r}, \boldsymbol{s})}{d s}+\kappa I(\boldsymbol{r}, \boldsymbol{s})=0
$$

where $I$ is the angular radiation intensity $\left[\mathrm{W} \mathrm{m}^{-2} \mathrm{sr}^{-1}\right], \boldsymbol{r}$ is the position vector, $\boldsymbol{s}$ is the direction vector and $\kappa$ is the absorption coefficient $\left[\mathrm{m}^{-1}\right]$. Only the direction normal to the free surface of the liquid of the RTE was modeled ( $y$ direction), i.e., direct radiation was assumed. Note that when the RTE is solved for only one direction, the radiation intensity is equivalent to the solar irradiance, $E_{p, o},\left[\mathrm{~W} \mathrm{~m}^{-2}\right]$.

The absorption coefficient was calculated summing the contribution from each absorbing species, $F e^{3+}-E D D S$ and $F e^{3+}-E D D S_{o x}$ (Eq. (20)), while the photon absorption of all other chemical species were neglected due their insignificant contribution in the radiation field.

$$
\kappa=\kappa_{F e^{3+}-E D D S}^{*}\left[F e^{3+}-E D D S\right]+\kappa_{F e^{3+}-E D D S_{o x}}^{*}\left[F e^{3+}-E D D S_{o x}\right]
$$

In Eq. (20), $\kappa_{F e^{3+}-E D D S}$ and $\kappa_{F e^{3+}-E D D S_{o x}}^{*}$ are the spectral-averaged molar Napierian absorption coefficient in $\left[\mathrm{M}^{-1} \mathrm{~m}^{-1}\right]$ of the $F e^{3+}-E D D S$ complex and of the oxidized $F e^{3+}-$ EDDS complex, respectively. Then, following the solution of the RTE, the LVRPA of the absorbing species, in $\left[\mathrm{E} \mathrm{m}^{-3} \mathrm{~s}^{-1}\right]$, can be computed by:

$$
\begin{aligned}
& L V R P A_{F e^{3+}-E D D S}=I \kappa_{F e^{3+}-E D D S}^{*}\left[F e^{3+}-E D D S\right] \frac{\lambda}{h c N_{A}} \\
& L V R P A_{F e^{3+-E D D S}}=I \kappa_{F e^{3+}-E D D S}^{*}\left[F e^{3+}-E D D S_{O x}\right] \frac{\lambda}{h c N_{A}}
\end{aligned}
$$


where $\lambda$ is the average wavelength of solar radiation, $h$ is the Planck constant, $c$ is the speed of light and $N_{A}$ is the Avogadro constant. It is noteworthy the units of $L V R P A$ in the reactions $\mathrm{R}_{1}$ and $\mathrm{R}_{7}$ must be in $\left[\mathrm{E} \mathrm{L}^{-1} \mathrm{~s}^{-1}\right]$.

\subsection{Numerical procedure}

The computational mesh was generated using hexahedral elements to minimize the numerical diffusion along the liquid depth where a mesh refinement is required. The independence of the mesh size was studied analysing both fluid flow and chemical reactions (shown in Figure S6, SI), and the results indicated that refinements above 295.000 elements did not change the CFD results.

ANSYS Fluent R2020 was used to solve the reacting flow in the RPR by a two-step simulation procedure. First, the turbulent flow was solved under steady state. Then, this result was combined with the solutions of the species transport equations and with the solution of the RTE to compute the degradation of the target CECs. Note that the flow and the species transport could be computed separately, since the flow properties were not affected by the concentration of the chemical species and neither by the radiation transport.

The RTE was solved only in the y-direction, since direct solar radiation, normal to the surface of the water, was assumed, thus, the RTE solution was carried out using an additional transport equation (User-Defined Scalar) in order to reduce the computational time. Comparing the solution with UDS and the analytical solution (Beer-Lambert law), presented in Fig. S7 (SI) no substantial differences were observed, which validated the proposed approach. Flowchart describing the numerical procedure of the SD model for the determination of the RTD, the mixing time and the solution of the photo-Fenton process are shown in Fig. S8 (SI).

The boundary conditions of the fluid flow model were: (a) constant velocity at the reactor inlet pipe and turbulence intensity of 5\%; (b) Constant pressure at the reactor outlet 
pipe equal to $0 \mathrm{~Pa}$ (open to atmosphere); (c) free-slip condition at the top wall (free-surface region); (d) no-slip conditions at the remaining walls of the reactor. The solution of the species transport and radiation transport was performed either under steady-state or under transient conditions, depending on the scenario evaluated. The boundary conditions adopted for the species transport equations were: (e) constant concentrations at the reactor inlet (values shown in Table 1) and (f) zero-diffusive flux at all other boundaries. The boundary condition for the RTE was set at the free surface: $(\mathrm{g})$ constant intensity of incident radiation.

The flow and turbulence equations were solved with convergence criterion as minimum residuals below $1 \cdot 10^{-3}$. In the transient VOF/SM simulations, the time-step adopted was 0.005 s. For the species transport and RTE, the numerical method convergence criterion was taken as minimum residuals below $1 \cdot 10^{-6}$ and the time-step (for the transient analyses) was $0.5 \mathrm{~s}$.

\section{Results and Discussion}

\subsection{Characterization of hydrodynamics in the raceway pond reactor}

Fig. 1 shows the hydrodynamic field in the RPR at half liquid depth $(y=0.025 \mathrm{~m})$ calculated using the VOF/SM and the SD models for the reactor operating in batch mode. The CFD solution of the multiphase flow using the VOF/SM model at the paddle rotational speed of $22 \mathrm{rpm}$ presented an oscillatory flow pattern with mean circulation velocity of $0.16 \mathrm{~m} / \mathrm{s}$ (Fig. 1 (a)). The amplitude of the velocity waves varied from $15 \%$ of mean circulation velocity ( \pm $0.025 \mathrm{~m} / \mathrm{s}$ ) in front of the paddle wheel to $3 \%$ of the mean circulation velocity, further away from the paddle wheel on the opposite side of the RPR. The attenuation of flow waves is caused by turbulent dissipation (Froude number lower than 1). Moreover, the CFD results revealed the presence of two stagnant zones in the RPR, that were located after the bends. The more prominent stagnant zone was observed after the bend on the opposite side of the paddle wheel 
(right side of the RPR in Fig. 1), while another smaller stagnant zone was observed behind the paddle wheel.

Comparing the time-averaged solutions using the VOF/SM model and the Source Domain (SD) model, the SD model computed larger stagnant zone areas, due to the neglection of the turbulent mixing generated by the oscillatory flow behavior. However, the SD achieved steady-state solutions in approximately 4 hours of parallel processing (8 CPUs) whilst the VOF/SM model computed time-averaged fields, averaged over 25 seconds of simulated time, in 164 hours using the same CPUs. Thus, the SD model produced a 41 -fold reduction on the computational time. Furthermore, the momentum source model had a very good match with the time-averaged solution using the VOF/SM model, as showed by Fig. 1.

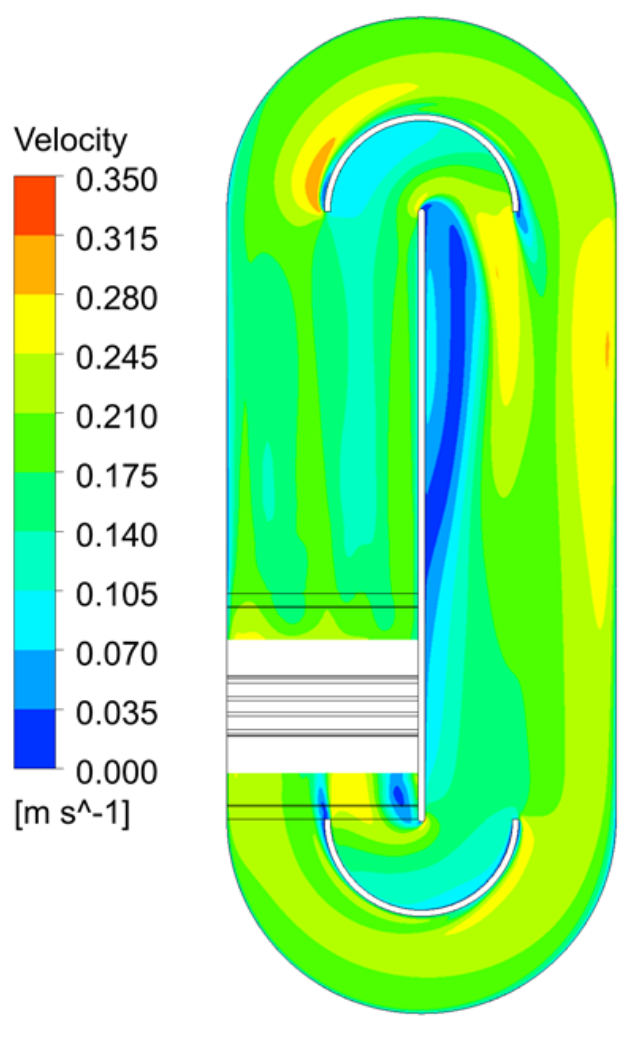

(a)

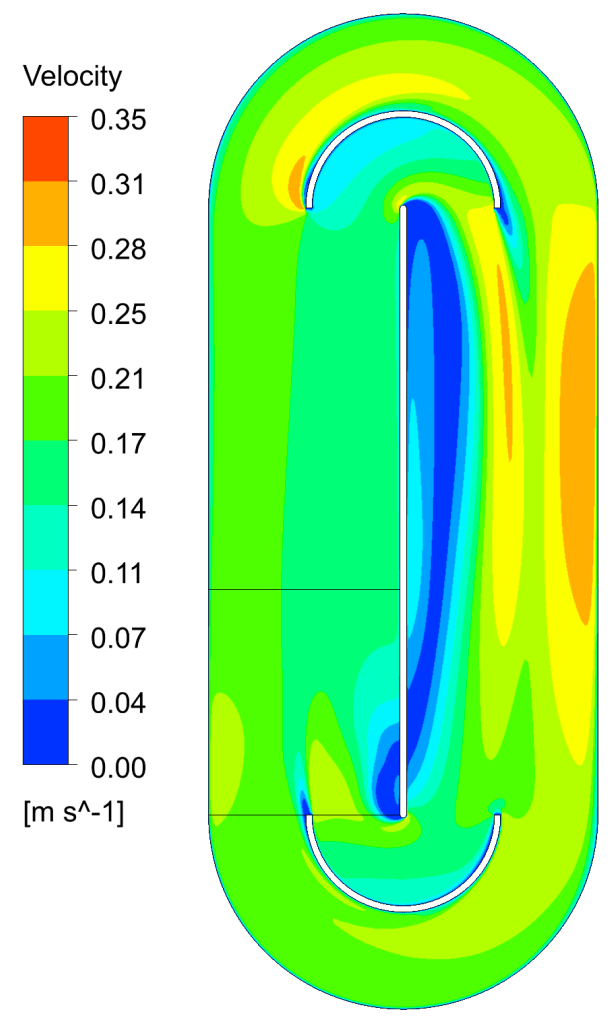

(b)

Fig. 1. Velocity profile at the plane located at the mid plane over $y$-direction $(y / d=$ 0.5) for the (a) time-averaged transient simulation with the VOF/SM model and the (b) SD model. Results obtained for the reactor operating under batch mode. 


\subsubsection{Determination of the mixing time in batch mode}

The mixing time in the RPR was computed by a pulse response analysis using the VOF/SM and the SD models, and these were compared with experimental measurements (Fig. 2). Numerically, this problem was solved by the species transport equation of a non-reacting numerical tracer (Eq. (16)) using the dynamic concentrations measured at the same three positions, until the computation of the coefficient of variation of the tracer concentration $(C)$ in the RPR ( $\mathrm{CoV})$, reached 0.05 , which corresponds to $95 \%$ of homogenous mixing [32]:

$$
\operatorname{CoV}=\sqrt{\frac{\int_{V}\left[\frac{(C-\bar{C})}{\bar{C}}\right]^{2} d V}{\int_{V} d V}}
$$

The experimental mixing time $\left(\theta_{m}^{e x p}\right)$ was $60 \mathrm{~s}$, while the mixing time determined by

CFD was $70.77 \mathrm{~s}\left(\theta_{m}^{V O F / S M}\right)$ by VOF/SM model and $106.5 \mathrm{~s}$ by SD model $\left(\theta_{m}^{S D}\right)$. Computing the mixing time through the $C o V$, the $\theta_{m}^{V O F / S M}$ was $68.60 \mathrm{~s}$ and the $\theta_{m}^{S D}$ was $100.00 \mathrm{~s}$ (Fig. S9, SI). The curves of the tracer concentration (presented as $\mathrm{pH}$ ) at the measurement points over time are shown in Fig. 2. The results using the VOF/SM model showed an excellent match with the experimental mixing time in the RPR. On the other hand, the SD model predicted a mixing time $45 \%$ higher than the VOF/SM due to the larger stagnation zone and due to the neglection of the micro-mixing resultant from the oscillatory flow.

However, the VOF/SM model required 20 days of computational time, using $8 \mathrm{CPUs}$, to simulate 76 seconds of physical time, whereas the SD model solved the same problem in less than 8 hours. Hence, the momentum source SD model was selected to model the removal of CECs by the solar photo-Fenton process since this model provided fair accuracy and a significant reduction in computational time. The results are further presented as function of the 
mixing time $\left(\theta_{m}\right)$ in order to assess the impact of mixing in the RPR on the solar photo-Fenton process, independently of reactor geometry, paddle wheel geometry or its rotational speed.

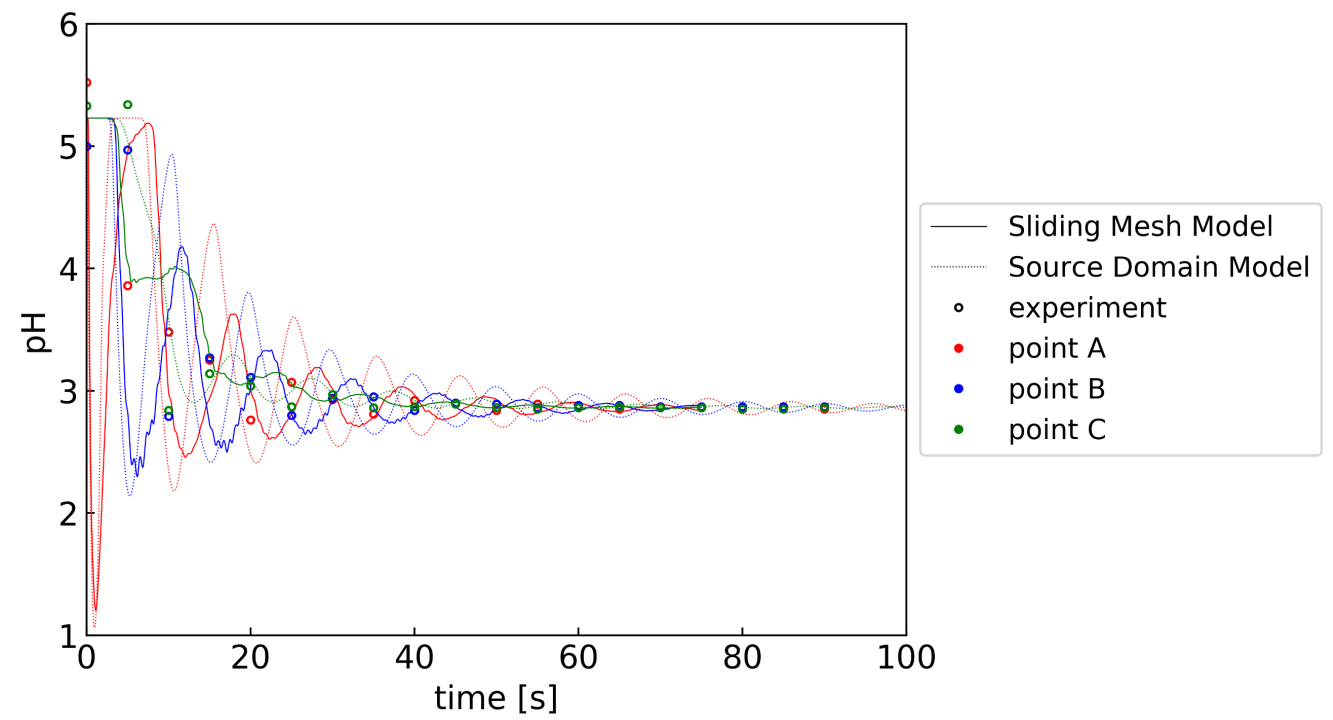

Fig. 2. Determination of the mixing time at $N=22 \mathrm{rpm}$ : Comparison among the experimental measurements, the $\mathrm{VOF} / \mathrm{SM}$ model and the SD model at the monitoring points shown in Fig. S2, SI. Results obtained for the reactor operating under batch mode.

\subsubsection{Determination of the residence time distribution in continuous mode}

In analogy to the mixing time, which was computed under batch operational mode, the Residence Time Distribution (RTD) describes the macro-mixing pattern in the reactor under continuous flow mode. The RTD was, therefore, computed numerically by the injection of a non-reacting numerical tracer, solved by the transient method of Eq. (16), and by following the tracer concentration at the reactor outlet over time. The results in Fig. 3 shows a very high degree of bypassing in the RPR during the first 7 circulations of the numerical tracer (approximately 1 mixing time), regardless of the mean residence time. After this period of instability, the RTD approaches the behavior of a perfectly mixed CSTR, evidencing a low impact of the stagnant zones observed in Fig. 1 on the overall degree of macro-mixing. However, the knowledge of the RPR mixing time and RTD alone are insufficient to predict the 
removal of CECs in the reactor. An accurate prediction of the reactor performance requires the solution of the equations of fluid motion coupled with material transport and chemical reactions.

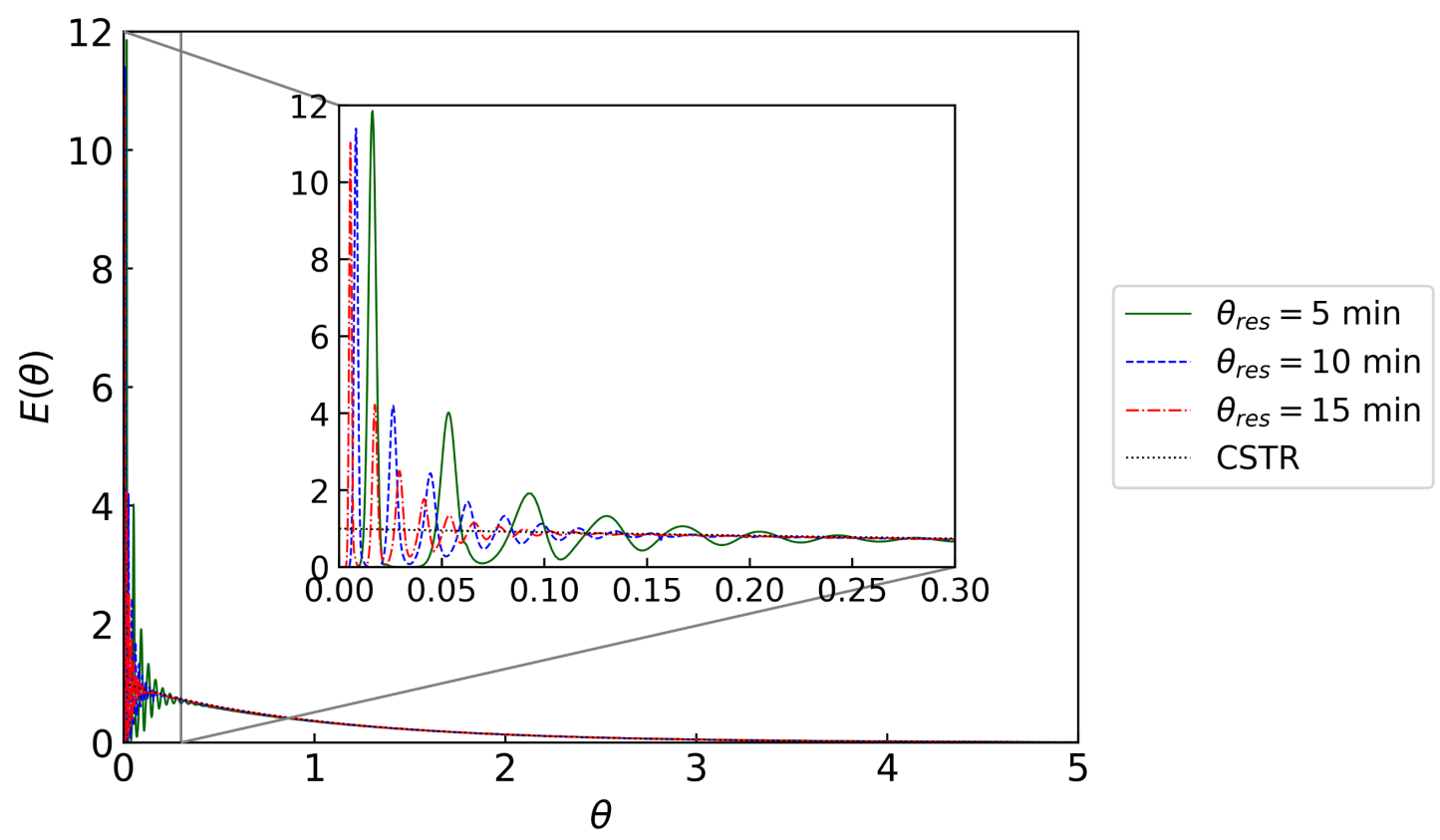

Fig. 3. RTD in the RPR for $\theta_{\text {res }}=5, \theta_{\text {res }}=10$ and $\theta_{\text {res }}=15(N=22 \mathrm{rpm})$.

\subsection{Solar photo-Fenton process under batch and continuous flow operational modes}

The CFD model coupled with the kinetic mechanism of the removal of CECs in the municipal WWTP effluents by the solar photo-Fenton process was solved in transient mode and the results were further compared with those predicted by the perfectly mixed model (CSTR). Although the degradation of CECs by the solar photo-Fenton processes followed a pseudo first-order kinetics $[25,20]$, departure from ideal CSTR behavior can arise not only from hydrodynamics features such as bypassing or recirculation zones, but also by the segregation of the reactant species in the reactor. Species segregation develops as a consequence of the different reaction rates inside the reactor, that occur due to the gradient of the LVRPA over the light pathlength, due to possible presence of zones under shadow (when 
the solar direct radiation direction is not perpendicular to the liquid surface), and due to local mixing shortcomings. A comparison of the CFD model to the experimental results (Fig. 4) shows that the model follows the experimental results.

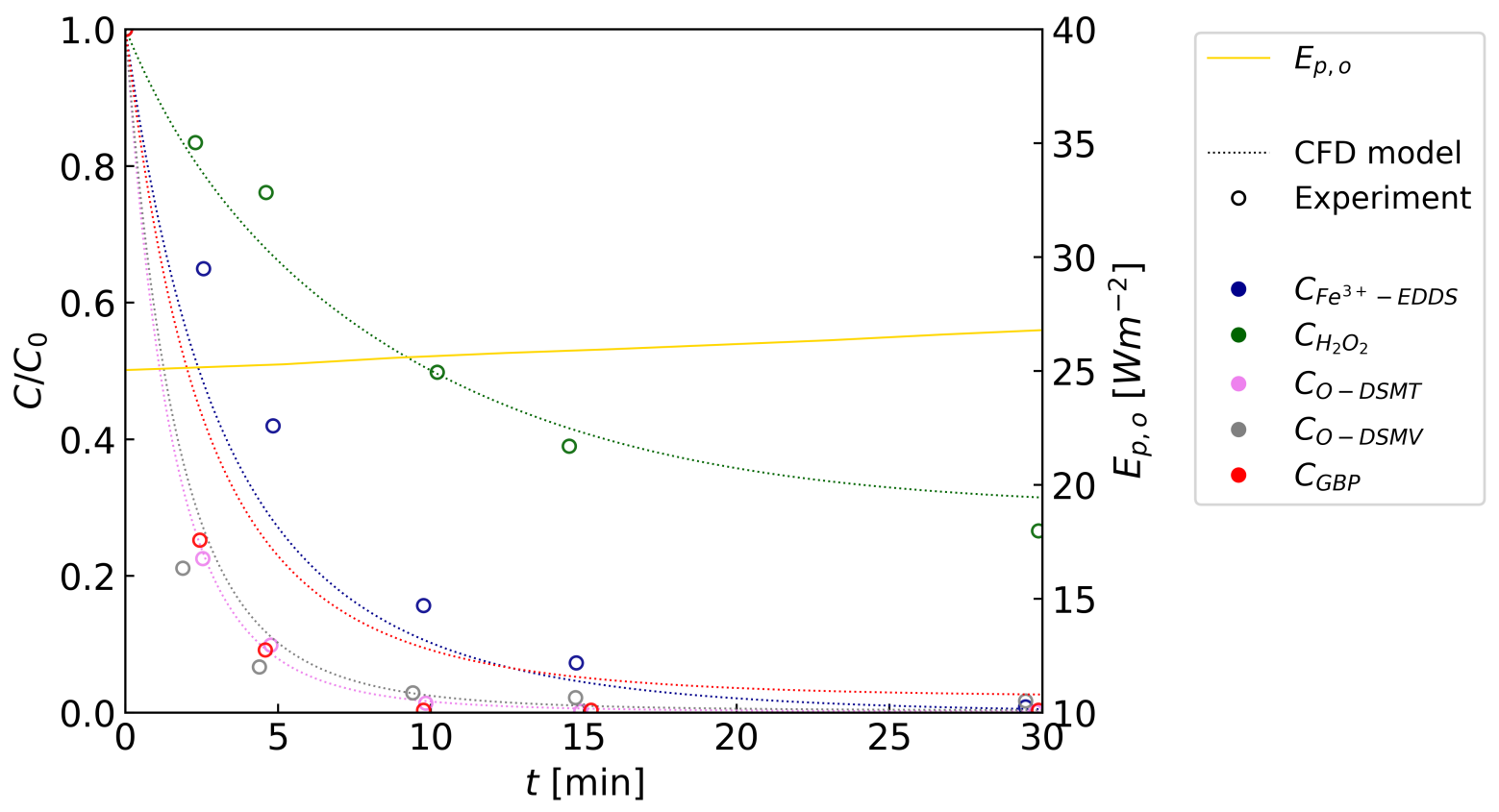

(a)

Fig. 4. Comparison between the CFD model and experimental data [19] for the photoFenton process at neutral $\mathrm{pH}(N=22 \mathrm{rpm})$ for a batch reactor mode.

Fig. 5 shows the CFD and the perfectly mixed model (CSTR) results for the degradation of the CECs under batch (Fig. 5 (a)) and under continuous flow operational modes (Fig. 5 (b)). Note that the simulation shown in Fig. 5 (b) relates to batch operation for the initial 30 min and subsequent continuous flow operation with $\left(\theta_{\text {res }}=15 \mathrm{~min}\right)$ from 30 to $150 \mathrm{~min}$ and $\left(\theta_{\text {res }}=\right.$ $10 \mathrm{~min}$ ) from 150 to 270 minutes [19]. The fractional conversion of $\mathrm{Fe}^{3+}$-EDDS and $\mathrm{H}_{2} \mathrm{O}_{2}$ under continuous flow operation decreased with HRT, from approximately $80 \%$ and $53 \%$ at a HRT of $15 \mathrm{~min}$, respectively, to approximately $70 \%$ and $43 \%$ at a HRT of $10 \mathrm{~min}$, respectively. This means that in the RPR outlet stream the reductive Fenton like reaction $\left(\mathrm{R}_{5}\right.$ in Table 2$)$ still proceeds to total consumption of the iron complex, giving rise to an additional decrease in the 
CEC concentration. The precipitated iron formed iron hydroxides flocs in suspension, which exited the reactor from the outlet stream, thus iron accumulation was not observed.

The results under batch operational mode (Fig. 5a) showed that both models presented similar degradation rates of CECs and similar consumption of the reactants $\mathrm{H}_{2} \mathrm{O}_{2}$ and $\mathrm{Fe}^{3+}-$ EDDS, however, this apparent match may deviate under continuous flow operation. The deviation from the ideal flow was, therefore, evaluated using the ratio between the reaction kinetics half-life time $\left(\theta_{0.5}\right)$ of CECs and the mixing time $\left(\theta_{0.5} / \theta_{m}\right)$ [33]. The half-life time of a first order reaction [33] is:

$$
\theta_{0.5}=\frac{\ln 2}{k_{a p p}}
$$

where $k_{a p p}$ is the apparent first order kinetics of a CEC.

When the reactor was operated under continuous flow (Fig. 5 (b)), the deviations from the ideal flow became more apparent due to the compounded effects of bypassing (Fig. 3) and non-homogeneous distribution of $\left[\mathrm{OH}^{\cdot}\right]$ in the RPR. 


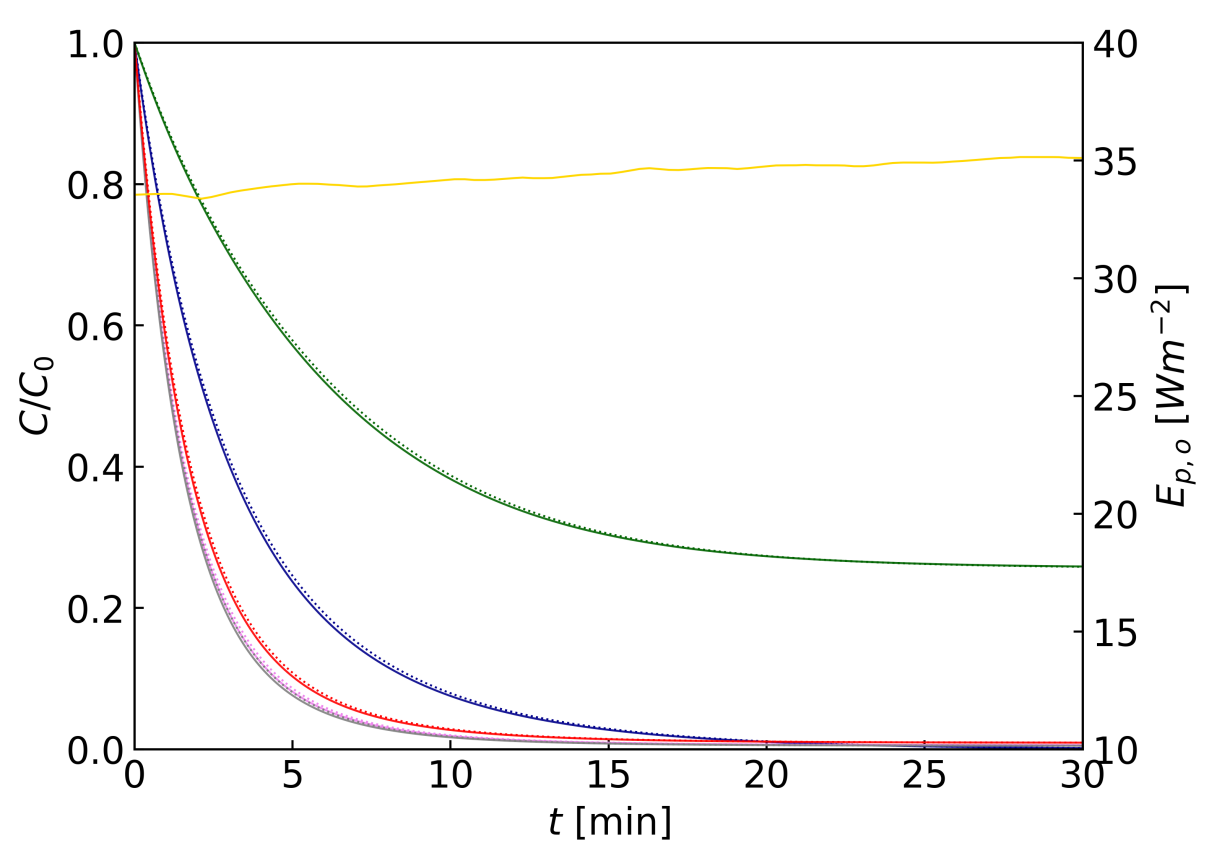

$$
\begin{aligned}
& E_{p, O} \\
- & \text { CSTR model } \\
\cdots \cdots \cdots \cdots . . & \text { CFD model } \\
\text { - } & C_{F^{3+}-E D D S} \\
\text { - } & C_{H_{2} O_{2}} \\
\text { - } & C_{O-D S M T} \\
\text { - } & C_{O-D S M V} \\
\text { - } & C_{G B P}
\end{aligned}
$$

(a)

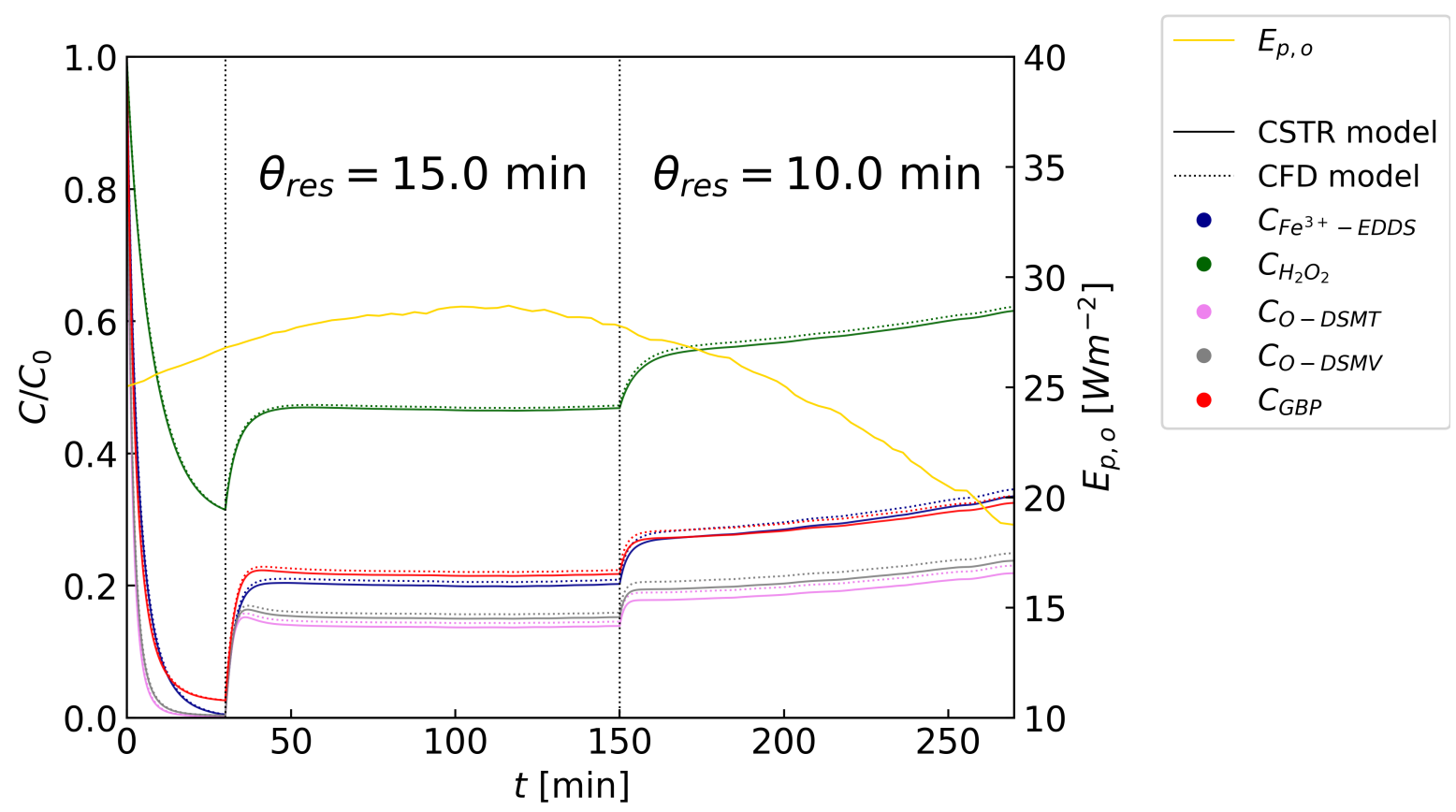

(b)

Fig. 5. Comparison between the CFD model and the CSTR model for the Photo-Fenton process at neutral $\mathrm{pH}(N=22 \mathrm{rpm})$ for (a) batch reactor and (b) batch mode from 0 to 30 minutes, continuous flow mode with $\theta_{\text {res }}=15$ min from 30 to 150 minutes and continuous flow mode with $\theta_{\text {res }}=10 \mathrm{~min}$ from 150 to 270 minutes. 


\subsection{Impact of hydrodynamics on the degradation of CECs under continuous flow mode}

As observed in Fig. 5, the local mixing can play an important role in the degradation of the CECs by the solar photo-Fenton process under continuous flow mode, which was more significant when the residence time decreased from 15 to $10 \mathrm{~min}$.

The removal of CECs was further evaluated as a function of the paddle wheel rotational speed (from 11 to $44 \mathrm{rpm}$ ), solar radiation (from 10 to $30 \mathrm{Wm}^{-2}$ ) and the residence time (from 5 to $25 \mathrm{~min})$. The results are described in terms of the ratio of the main timescales $\theta_{0.5} / \theta_{m}$ and $\theta_{\text {res }} / \theta_{m}$, to understand the impact of hydrodynamics on the CECs removal rates. Note that perfectly mixed conditions are expected to be achieved when both timescales ratios are much greater than one [33].

The dimensionless concentration profile of O-DSMT in the RPR for $N=22 \mathrm{rpm}$ and $E_{p, o}=30 \mathrm{~W} \mathrm{~m}^{-2}$ at different fluid residence times calculated by the SD model shown in Fig. 6 , revealed lower concentrations of O-DSMT at the stagnation zones, regardless of the $\theta_{\text {res }} / \theta_{m}$ ratio, due to longer recirculation and reaction times. Also, non-homogenous distribution of ODSMT was observed over the reactor width, which can be ascribed to poor mixing in this direction despite the turbulent flow pattern. As expected, the concentration profile of hydroxyl radicals along the reactor exhibited similar undesirable non-homogenous distribution (Fig. S10, SI), since the removal of CECs is a second-order reaction, even though commonly presented with an apparent first-order kinetics. Accordingly, deviations from the perfectly mixed reactor were observed, especially when $\theta_{0.5} / \theta_{m}<1$. 


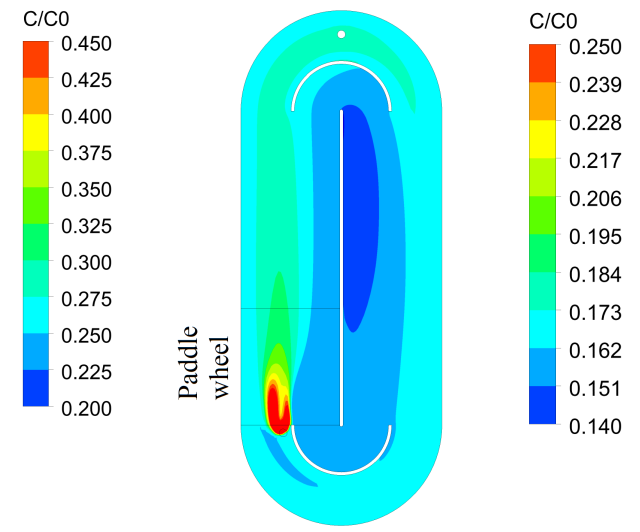

(a)

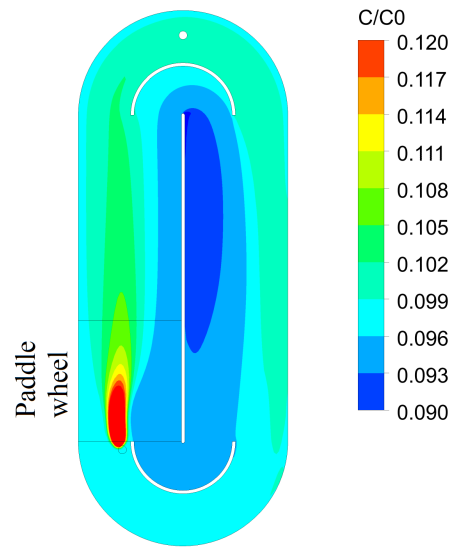

(b)

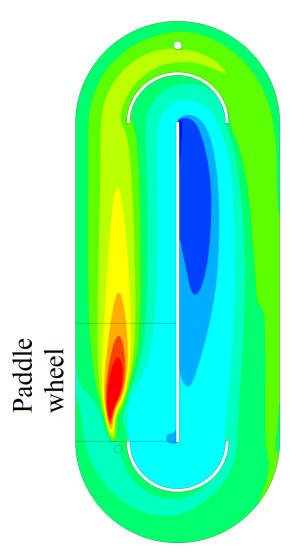

(c)

Fig. 6. Dimensionless concentration of O-DSMT at the plane located at $y / d=0.5$. (a) $\theta_{\text {res }}=5 \mathrm{~min}\left(\theta_{\text {res }} / \theta_{m}=3\right.$ and $\left.\theta_{0.5} / \theta_{m}=0.83\right)$, (b) $\theta_{\text {res }}=10 \mathrm{~min}\left(\theta_{\text {res }} / \theta_{m}=6\right.$ and $\left.\theta_{0.5} / \theta_{m}=0.92\right)$ and (c) $\theta_{\text {res }}=25 \min \left(\theta_{\text {res }} / \theta_{m}=15\right.$ and $\left.\theta_{0.5} / \theta_{m}=1.26\right) . E_{p, o}=30 \mathrm{~W}$ $\mathrm{m}^{-2}, N=22 \mathrm{rpm}$ and $\theta_{m}=1.67 \mathrm{~min}$.

Considering the deviations from the perfectly mixed reactor conditions, the effect of the mixing time in the RPR was studied by varying the paddle wheel rotational speed from 11 to $44 \mathrm{rpm}$. Table 3 presents the hydraulic power $\left(\mathrm{P}_{\mathrm{h}}\right)$ and mixing time $\left(\theta_{m}\right)$ for each rotational speed evaluated under a fixed $\theta_{\text {res }}(10 \mathrm{~min})$ and under fixed solar irradiation $\left(30 \mathrm{~W} / \mathrm{m}^{2}\right)$. It also shows the ratio between the reaction kinetics half-life time and the mixing time $\left(\theta_{0.5} / \theta_{m}\right)$ for each CECs and the quantitative deviation of the CFD model from the ideal CSTR model, in terms of ratio of apparent kinetics constants of CECs $\left(k_{a p p, C F D} / k_{a p p, C S T R}\right)$ and in terms of ratio of average concentration of $\mathrm{OH} \cdot\left(\overline{[O H}_{C F D} /[O H]_{C S T R}\right)$. In these simulations, the thrust and drag coefficients of the SD model were maintained constant, since, as a positive displacement pump, the paddle wheel provides a flow rate proportional to the rotational speed.

Table 3. Effects of the rotational speed of the paddle wheel on the performance of the solar photo-Fenton process for the removal of CECs $\left(\theta_{\text {res }}=10 \mathrm{~min}\right.$ and $\left.E_{p, o}=30 \mathrm{~W}\right)$. 
O-DSMT O-DSMV GBP

\begin{tabular}{ccccccccccc}
\hline$N[\mathrm{rpm}]$ & $P_{h}[\mathrm{~W}]$ & $\theta_{m}[\mathrm{~s}]$ & $\frac{\theta_{\text {res }}}{\theta_{m}}$ & & $\frac{\theta_{0.5}}{\theta_{m}}$ & & & $\frac{k_{\text {app }, C F D}}{k_{\text {app }, C S T R}}$ & & $\frac{\overline{[O H]}_{C F D}}{[\mathrm{OHH}]_{C S T R}}$ \\
\hline & & & & O-DSMT & O-DSMV & GBP & O-DSMT & O-DSMV & GBP \\
\hline 11 & $5.84 \cdot 10^{-3}$ & 179.0 & 3.35 & 0.556 & 0.602 & 0.902 & 0.864 & 0.872 & 0.901 & 0.980 \\
22 & $4.74 \cdot 10^{-2}$ & 100.0 & 6.00 & 0.926 & 1.022 & 1.552 & 0.914 & 0.920 & 0.937 & 0.985 \\
33 & $1.60 \cdot 10^{-1}$ & 66.5 & 9.02 & 1.360 & 1.508 & 2.302 & 0.933 & 0.937 & 0.951 & 0.988 \\
44 & $3.78 \cdot 10^{-1}$ & 49.5 & 12.12 & 1.805 & 2.003 & 3.043 & 0.944 & 0.947 & 0.958 & 0.987 \\
\hline
\end{tabular}

The results showed significant impact of the mixing time on the degradation of the CECs in the RPR. The apparent kinetics of compounds degradation ( $\left.k_{a p p, C F D}\right)$ were up to 13.6 \% lower than the apparent kinetics in a perfectly mixed CSTR reactor $\left(k_{\text {app,CSTR }}\right)$, and the deviations increased further as $\theta_{m}$ increased. In addition, the deviations from the ideal CSTR for the O-DSMT and O-DSMV compounds were more significant compared with those for GBP, since the second order kinetics constants $\left(k_{12}\right.$ and $\left.k_{13}\right)$ of the two former compounds are 1.73 and 1.55 times higher, respectively, than the second order kinetic constant of the latter contaminant $\left(k_{14}\right)$. In the presence of high concentration of $\mathrm{OH} \cdot$ scavengers the deviations from the ideal flow solution should decrease since the CECs half-life time would increase. The ratio $\overline{[\mathrm{OH}]}_{\mathrm{CFD}} /[\mathrm{OH}]_{\mathrm{CSTR}}$ was also affected by the mixing time, although the differences compared with the ideal CSTR were lower than $2 \%$ for all cases. Nevertheless, the energy requirements, $\mathrm{P}_{\mathrm{h}}$, augmented sharply with the increase on the rotational speed (proportional to $N^{3}$ ).

\subsubsection{Impact of timescale ratios on the apparent reaction kinetic constants}

Fig. 7 shows the first-order kinetic constant ratio $\left(k_{a p p, C F D} / k_{a p p, C S T R}\right)$ of the CECs for all evaluated cases as function of the timescale ratios $\left(\theta_{\text {res }} / \theta_{m}\right)$ and $\left(\theta_{0.5} / \theta_{m}\right)$ and irradiance. As expected, the flow approached that of an ideal CSTR as the residence time increased (Fig. 
7a) due to smaller by-passing under larger $\theta_{\text {res }}$ and higher consumption of the iron complex, causing lower $\left[\mathrm{OH}^{\cdot}\right]$ in the RPR. On the other hand, the apparent kinetics constants may decrease by more than $10 \%$ when $\theta_{0.5} / \theta_{m}<1$, whereas ideal CSTRs conditions are approached only for very high values $\theta_{0.5} / \theta_{m}$ (Fig. 7b).

The results also show that at higher solar irradiances the ratio $k_{a p p, C F D} / k_{a p p, C S T R}$ decreased, thus, higher irradiances induces greater rates of reduction of $\mathrm{Fe}^{3+}$ to $\mathrm{Fe}^{2+}\left(\mathrm{R}_{1}\right.$ in Table 2) and therefore greater heterogeneity of species in the reactor. This also implies that the faster the contaminant reaction rate constant the higher the difference between CFD and CSTR models, giving rise to a higher impact of mixing at higher irradiances, an aspect particularly important for the design and operation of large-scale RPRs.

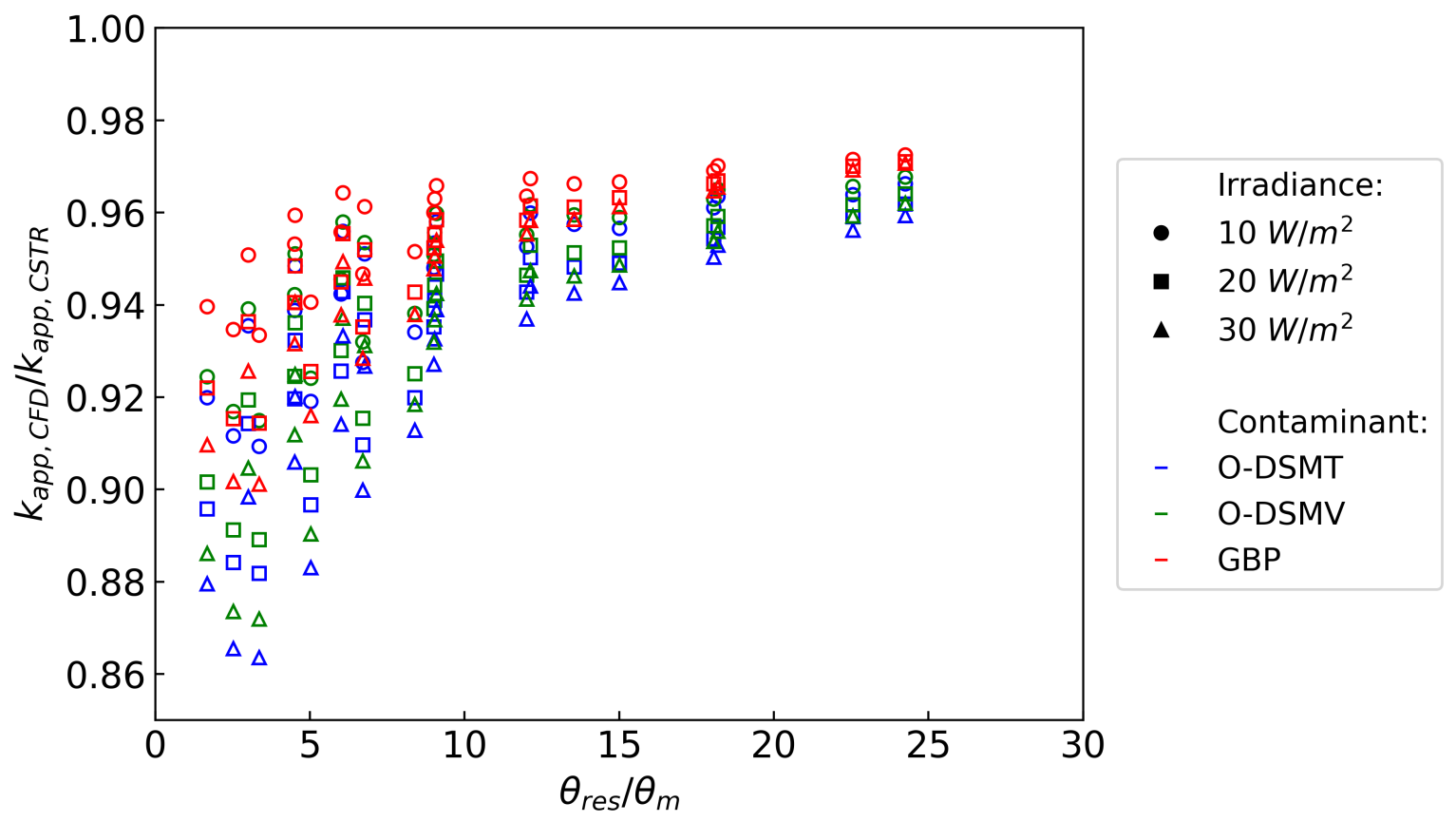

(a) 


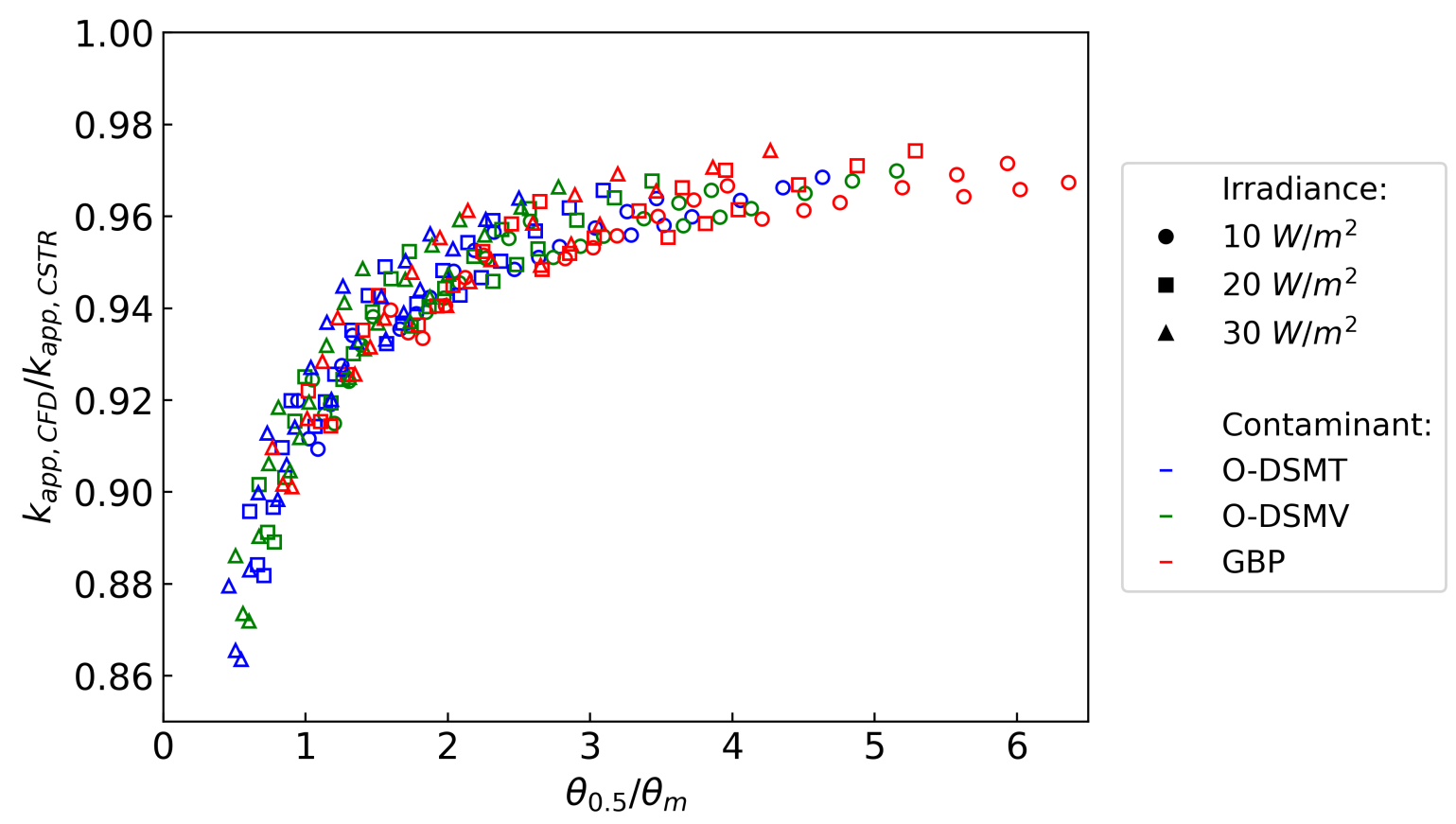

(b)

Fig. 7. Ratio between the CFD apparent first order kinetic constant and the CSTR apparent first order kinetic constant of the degradation of CECs versus (a) ratio between the residence time and the mixing time. and (b) ratio between the half-life time and the mixing time.

\subsubsection{Impact of reactor optical thickness}

The optical thickness $(\tau=\kappa d)$ measures the penetration of solar radiation over the liquid depth. The optical thickness of the pilot-scale RPR under the operating conditions investigated varied from 0.3 to 1.2 . Fig. 8 shows the concentration of $\mathrm{OH}$ radical and irradiance profiles over the reactor liquid depth for the case with $E_{p, o}=30 \mathrm{~W} \mathrm{~m}^{-2}$ and $N=22 \mathrm{rpm}$ and for $\theta_{\text {res }}=$ $5 \mathrm{~min}, \theta_{\text {res }}=10 \mathrm{~min}$ and $\theta_{\text {res }}=25 \mathrm{~min}$, illustrating the absence of dark zones. These observations indicated that the liquid depth in the RPR can be increased up to optimum optical thickness of approximately 3 [34], in order to improve the treatment capacity $(T C=Q / A)$. Furthermore, the concentration of CECs was pseudo-homogeneous over the liquid depth due 
to the turbulent diffusion (shown in Fig. S11, SI), supporting the scale-up of the reactor towards higher liquid depths.
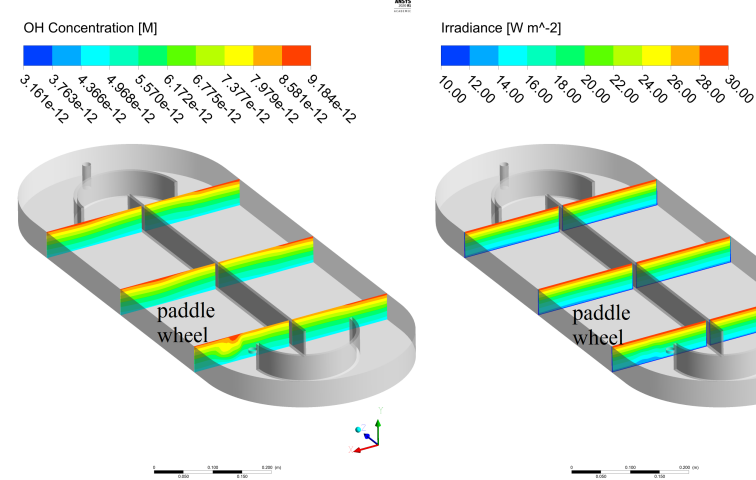

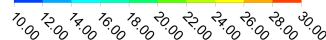

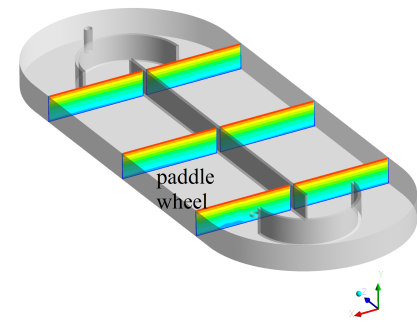

(a)

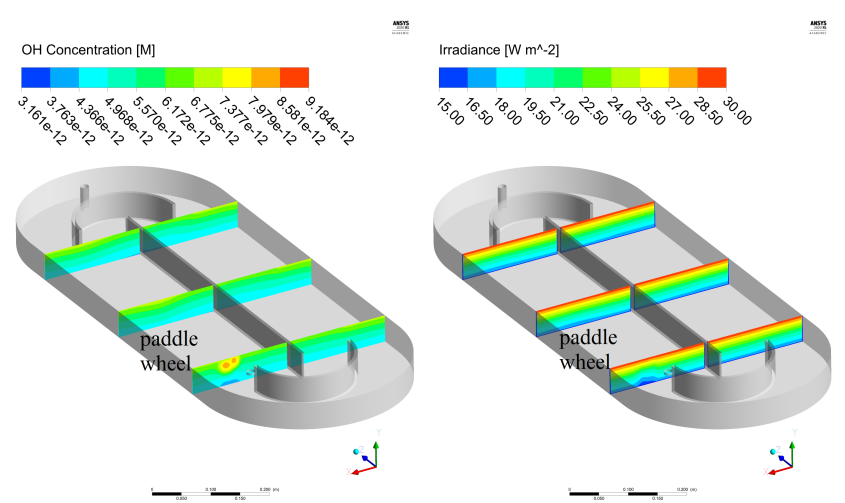

(b)

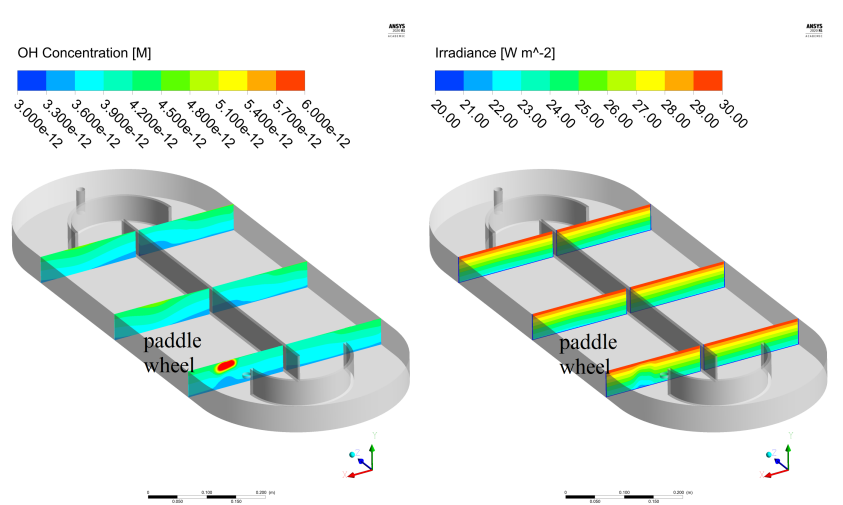

(c) 
Fig. 8. Concentration of hydroxyl radical and irradiance at the plane located at $z=0.0$ $\mathrm{m}$ (center plane), $z=-0.25 \mathrm{~m}$ and $z=0.25 \mathrm{~m}$. (a) $\theta_{\text {res }}=5 \mathrm{~min}$, (b) $\theta_{\text {res }}=10 \mathrm{~min}$ and (c) $\theta_{\text {res }}=25 \min . E_{p, o}=30 \mathrm{~W} \mathrm{~m}^{-2}, N=22 \mathrm{rpm}$ and $\theta_{m}=1.67 \mathrm{~min}$.

\subsection{Impact of hydrodynamics on the degradation of CECs in a scaled-up RPR}

The model developed in this study was used to examine the impact of mixing and liquid depth in a scaled-up RPR to determine the feasibility of constructing large scale reactors and to formulate generalized design criteria. The length and width of the RPRs were increased by a factor of 5 (thus an area 25 times higher than the pilot-scale reactor) and the liquid depth were $150 \mathrm{~mm}, 200 \mathrm{~mm}$ and $250 \mathrm{~mm}$. The treatment capacity $(Q / A)$, among the pilot-scale and the scaled-up RPRs, was kept constant in the scaling-up procedure, by varying the $\theta_{\text {res }}$ and the flow rate $Q$. Table 4 show the geometry, the scale-up factors, the operating conditions and main results of the pilot-scale and the scaled-up RPRs. The results demonstrate that the solar photoFenton process in large-scale RPRs also achieve effective removal of CECs. The results showed that greater liquid depths improved the removal of CECs by increasing the reactor volume and therefore the optical thickness approaching optimum values [34]. This is more evident when steady-state concentration of CECs $\left(C / C_{0}\right)$ at the reactor exit was compared between the pilot-scale and the scaled-up RPRs. However, the removal of CECs barely increased from $d=0.20 \mathrm{~m}$ to $d=0.25 \mathrm{~m}$, indicating a saturation of light absorption at $d>$ $0.25 \mathrm{~m}$, since optimum optical thicknesses (approximately 3 ) were approached.

In addition, the large-scale reactors showed identical $k_{a p p, C F D} / k_{a p p, C S T R}$ values, in spite of the fact that the $\theta_{0.5} / \theta_{m}$ approximately increased by one fold in the large-scale RPRs. This can be interpreted as a decline in the RPR performance due to poorer mixing over the liquid depth direction, which could not be observed in the pilot-scale RPR. The reactor with the greatest liquid depth $d$ is affected by reduced mixing over the depth direction. The impact 
of irradiance and [OH'] for the evaluated scenarios are shown in Fig. S12 and Fig. S13 (SI).

Note that the liquid depth is an important operating condition that can be easily varied in RPRs to match optimal optical thickness (approximately 3) [34].

Table 4. Pilot-scale and Large-scale RPRs for liquid depth of $50 \mathrm{~mm}$ (pilot-scale) and 150, 200 and $250 \mathrm{~mm}$ (Large-scale). Solar radiation was fixed in $30 \mathrm{Wm}^{-2}$.

\begin{tabular}{|c|c|c|c|c|c|c|}
\hline & & $\begin{array}{l}\text { Pilot } \\
\text { scale }\end{array}$ & $\begin{array}{l}\text { Large- } \\
\text { scale } \\
\mathrm{d}=0.15 \mathrm{~m}\end{array}$ & $\begin{array}{l}\text { Large } \\
\text { Scale } \\
\mathrm{d}=0.20 \mathrm{~m}\end{array}$ & $\begin{array}{l}\text { Large- } \\
\text { scale } \\
\mathrm{d}=0.25 \mathrm{~m}\end{array}$ & Scale-up factors \\
\hline \multirow{5}{*}{ 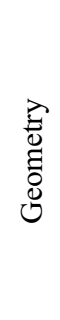 } & Length $[\mathrm{m}]$ & 1.00 & 5.00 & 5.00 & 5.00 & $5 \mathrm{x}$ \\
\hline & Width $[\mathrm{m}]$ & 0.19 & 0.94 & 0.94 & 0.94 & $5 \mathrm{x}$ \\
\hline & Reactor area $\left[\mathrm{m}^{2}\right]$ & 0.33 & 8.25 & 8.25 & 8.25 & $25 \mathrm{x}$ \\
\hline & Liquid depth $[\mathrm{m}]$ & 0.05 & 0.15 & 0.20 & 0.25 & $3 x, 4 x$ and $5 x$ \\
\hline & Paddle wheel radius $[\mathrm{m}]$ & 0.10 & 0.40 & 0.40 & 0.40 & $4 \mathrm{x}$ \\
\hline \multirow{5}{*}{ 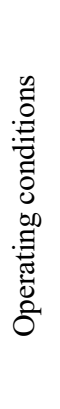 } & Paddle wheel rotational speed [rpm] & 22.00 & 22.00 & 22.00 & 22.00 & $1 \mathrm{x}$ \\
\hline & Hydraulic power $\left(P_{h}\right)[\mathrm{W}]$ & $4.74 \cdot 10-2$ & 62.53 & 65.22 & 62.53 & $1300 x$ \\
\hline & $\begin{array}{l}\text { Hydraulic power per unit volume } \\
{\left[\mathrm{W} \mathrm{m}^{-3}\right]}\end{array}$ & 2.87 & 50.53 & 37.90 & 30.31 & $\begin{array}{l}17.6 \mathrm{x}, 13.2 \mathrm{x} \text { and } \\
10.6 \mathrm{x}\end{array}$ \\
\hline & Mean residence time $\left(\theta_{\text {res }}\right)[\mathrm{min}]$ & 5.00 & 15.00 & 20.00 & 25.00 & $3.0 \mathrm{x}, 4.0 \mathrm{x}$ and $5.0 \mathrm{x}$ \\
\hline & $\begin{array}{l}\text { Treatment capacity }(Q / A)\left[\mathrm{L} \mathrm{min}{ }^{-1}\right. \\
\left.\mathrm{m}^{-2}\right]\end{array}$ & 10.04 & 10.04 & 10.04 & 10.04 & $1 \mathrm{x}$ \\
\hline \multirow{12}{*}{$\frac{\mathscr{n}}{\vec{\Xi}}$} & Mixing time $[\mathrm{s}]$ & 100.00 & 94.00 & 110.00 & 116.00 & - \\
\hline & Optical thickness & 0.86 & 1.82 & 2.21 & 2.57 & - \\
\hline & $\theta_{\text {res }} / \theta_{m}$ & 3.00 & 9.57 & 10.91 & 12.93 & - \\
\hline & $\theta_{0.5} / \theta_{m}(\mathrm{O}-\mathrm{DSMT})$ & 0.80 & 1.53 & 1.55 & 1.69 & - \\
\hline & $\theta_{0.5} / \theta_{m}(\mathrm{O}-\mathrm{DSMV})$ & 0.89 & 1.69 & 1.71 & 1.87 & - \\
\hline & $\theta_{0.5} / \theta_{m}(\mathrm{GBP})$ & 1.35 & 2.56 & 2.59 & 2.85 & - \\
\hline & $k_{a p p} / k_{a p p, C S T R}(\mathrm{O}-\mathrm{DSMT})$ & 0.90 & 0.90 & 0.90 & 0.91 & - \\
\hline & $k_{a p p} / k_{a p p, C S T R}(\mathrm{O}-\mathrm{DSMV})$ & 0.90 & 0.90 & 0.91 & 0.91 & - \\
\hline & $k_{a p p} / k_{a p p, C S T R}(\mathrm{GBP})$ & 0.93 & 0.93 & 0.93 & 0.93 & - \\
\hline & $C / C_{0}(\mathrm{O}-\mathrm{DSMT})$ & 0.29 & 0.19 & 0.17 & 0.16 & - \\
\hline & $C / C_{0}(\mathrm{O}-\mathrm{DSMV})$ & 0.30 & 0.20 & 0.19 & 0.17 & - \\
\hline & $C / C_{0}(\mathrm{GBP})$ & 0.39 & 0.28 & 0.26 & 0.24 & - \\
\hline
\end{tabular}


As the required mixing power to maintain a certain degree of mixing time significantly increase with reactor volume, the same should be expected for a scaled-up RPR. With a paddle wheel 4 times larger than paddle wheel used in the pilot-scale RPR, the mixing time was kept approximately the same, however, the hydraulic power $P_{h}$ significantly increased (1300-fold higher) in the scaled-up RPR. This result raises important questions concerning scale-up factors for the paddle wheel and RPR, due to potential impact on the process economics. For example, an increase of reactor length should be preferred instead of an increase of the reactor width to reduce the power requirement [31]. In contrast, larger lengths require an increase on the rotational speed to maintain the same mixing time. Moreover, the required shaft power can be higher than the hydraulic power if the efficiency of the paddle wheel decreases over time. It should be noted that the paddle wheel is considered the most adequate mixing system for microalgae cultivation, however, the operational requirements for solar photo-Fenton process are significantly different and large-scale RPRs may need new mixing system designs.

\subsubsection{Removal rate of CECs versus residence time in large-scale RPRs}

Fig. 9 shows the CECs removal rates per unit of $C_{0}$ and the CECs conversions for both CFD and ideal CSTR models, for $\theta_{\text {res }}$ from 5 to $35 \mathrm{~min}$, for two irradiances $\left(E_{p, o}=10\right.$ and $\left.E_{p, o}=30 \mathrm{Wm}^{-2}\right)$ and for three liquid depths $(d=0.10 \mathrm{~m}, d=0.20 \mathrm{~m}$ and $d=0.25 \mathrm{~m})$. The CECs removal rate was higher at higher liquid depths, as previously shown, and it was higher at shorter residence times, since the apparent CECs reaction-order was higher than 0 , thus smaller conversions resulted in higher removal rates. However, the CFD model always predicted lower removal rates and conversions than the CSTR model due to the non-ideal mixing conditions, which becomes more important at larger reactor scales. Therefore, an increase on the liquid depth to match optimal rate of photon absorption (optical thickness approximately equal to 3 ) should be compensated by a proportional increase on the $\theta_{\text {res }}$ in 
order to achieve equal conversions. Moreover, an additional increment on the fluid residence time is needed to compensate the hydrodynamics deviations from the ideal CSTR.

The results presented of CECs removal by the solar photo-Fenton process in large-scale RPRs under continuous flow unveiled important insights for the designing of large-scale RPRs. The results showed that poor mixing reduces the reactor treatment capacity of CECs. For example, in the scaled-up geometries studied, the treatment capacity to achieve $80 \%$ of CECs removal fell by 9 to $10 \%$ compared with the ideal CSTR. While the reactor surface area (footprint) is the main investment cost of the solar RPR, operating costs such as the energy consumption to move the fluid can significantly increase when scaling-up from small to largescale reactors to achieve the required mixing time. On the other hand, sharp losses on the reactor performance are expected when $\theta_{0.5} / \theta_{m}<1$. 


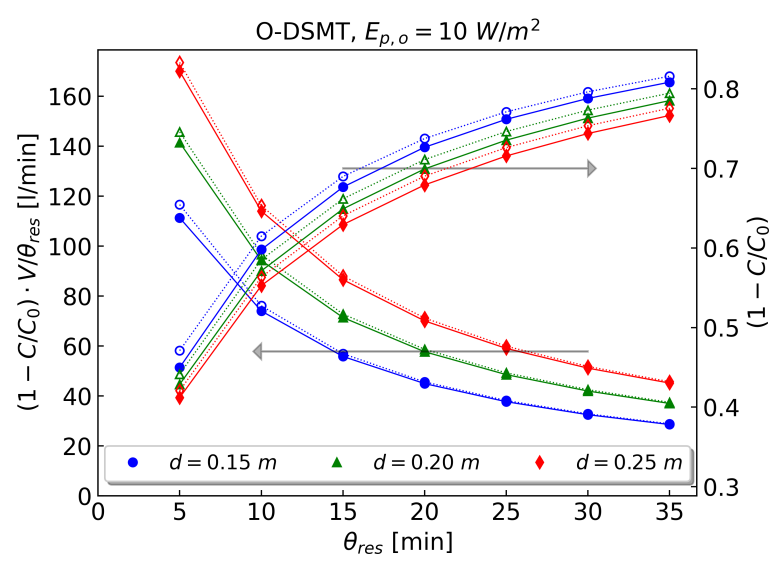

(a)

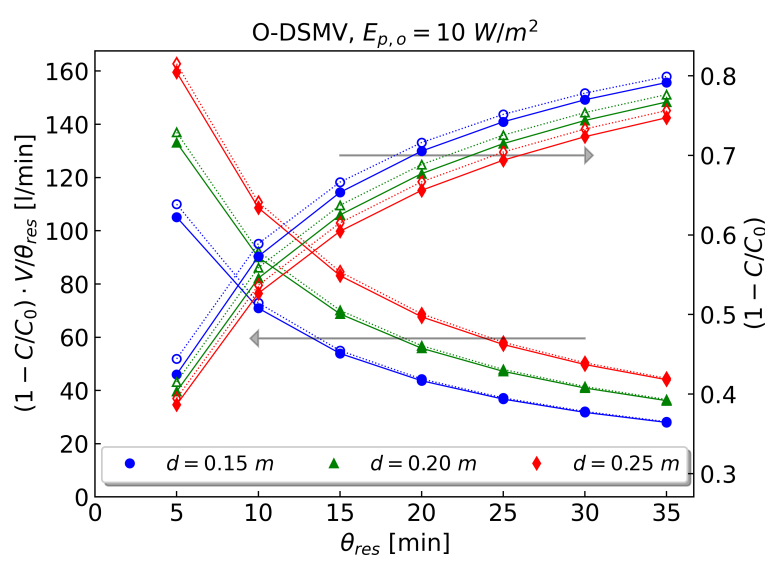

(c)

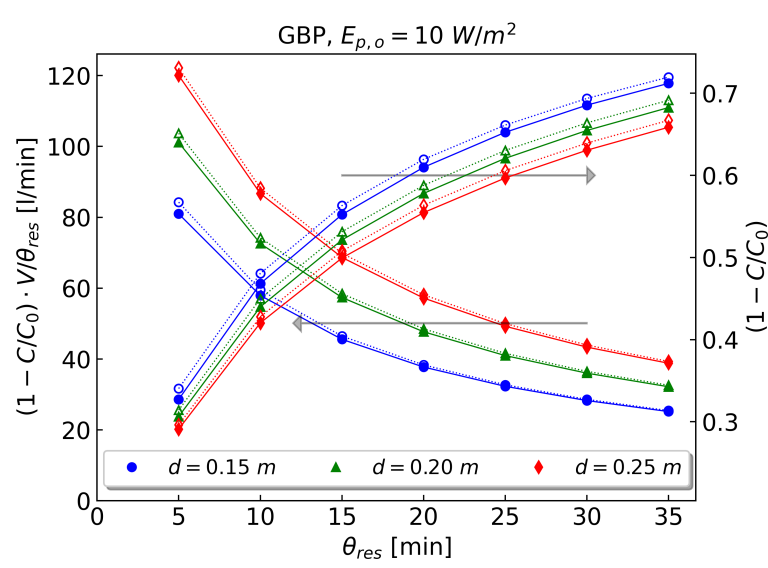

(e)

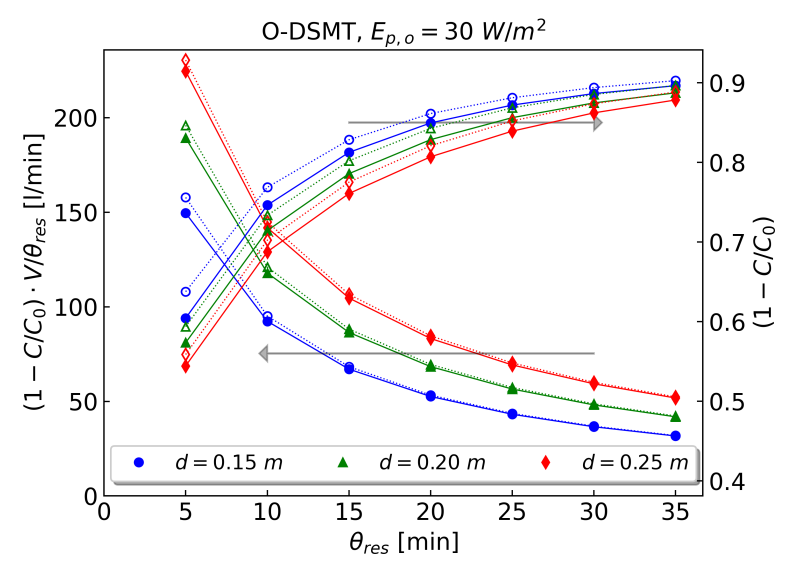

(b)

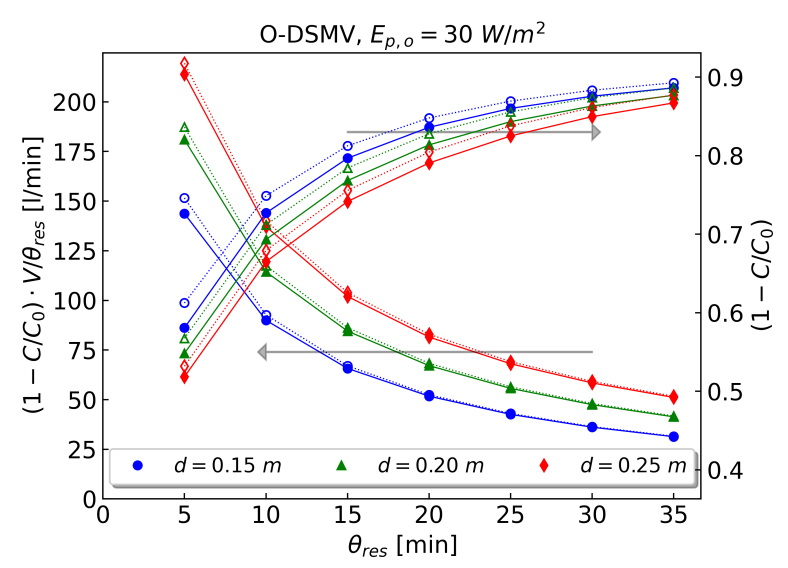

(d)

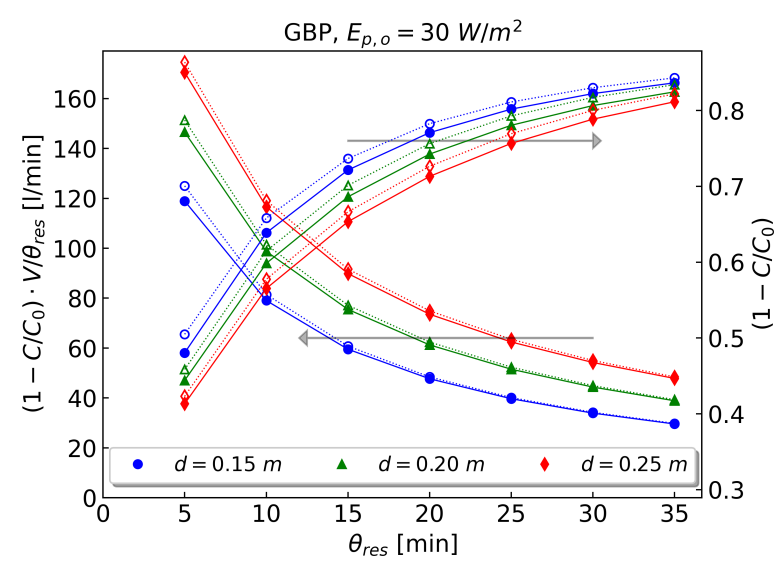

(f)

Fig. 9. CECs removal rate per unit of $C_{0},\left(\left[1-C / C_{0}\right] \cdot V / \theta_{\text {res }}\right)$ and CECs conversion $\left(\left[1-C / C_{0}\right]\right)$ as function of fluid residence time $\theta_{\text {res }}$ for $E_{p, o}=10 \mathrm{Wm}^{-2}$ and $E_{p, o}=30 \mathrm{Wm}^{-}$ 
2 calculated with CFD and ideal CSTR models. Continuum line and filled symbols: CFD; Dashed line and opened symbols: ideal CSTR.

\section{Conclusions}

This study has demonstrated the impact of mixing and hydrodynamics on the removal of contaminants of emerging concern (CECs) detected in a secondary WWTP effluent by the solar photo-Fenton process in a pilot scale RPR. The fluid flow field was accurately modeled by CFD and the computational time was reduced by 41 -fold by using a steady-state momentum source domain $(\mathrm{SD})$ model rather than a transient-multiphase flow mode. It was revealed that the transient oscillatory flow developed by the paddle wheel contributes significantly to the macromixing in the RPR. Furthermore, the turbulent flow in the RPRs exhibited adequate turbulence to achieve homogeneous mixing of the species over the liquid depth, reducing the impact of the radiation gradient. However, the presence of bypassing and stagnation zones adversely affected the reactor hydrodynamics.

The CFD model incorporating the solar photo-Fenton CECs oxidation kinetics, the radiation transport through the water, and the turbulent flow field produced by the paddle wheel mixer predicted the removal of CECs under transient and steady state conditions. The model unveiled the impact of the paddle wheel rotational speed, the fluid residence time $\left(\theta_{\text {res }}\right)$ and the solar radiation conditions on the treatment efficiency of the RPR at pilot-scale and in a scaled-up RPR. The results have shown that the apparent reaction kinetics deviated from that of an ideal CSTR by more than $10 \%$ when the ratio between the half-life time of the CECs and the mixing time was lower than 1.

The interest in the use of RPRs for the treatment of secondary WWTP effluents by the solar photo-Fenton process has increased in recent years due to very low operational and capital costs and easy process control. This study revealed that the design of hydrodynamics in large- 
scale RPRs must be carefully examined to reduce power consumption while increasing mixing performance. Although the reactor footprint is the highest fixed investment cost of the solar RPR, the energy consumption to pump the fluid and achieve the turbulent mixing requirements can significantly increase when scaling-up the reactors. It is likely that alternative RPRs mixing systems would need to be designed to carry out efficient photo-Fenton treatment of contaminated water, since common paddle wheels mixing devices do not scale favorably in terms of the power requirement. Moreover, the optimization of the RPRs length-to-width ratio, bend design and the promotion of oscillatory wavy flow may contribute to reduce the energy requirement for the mixing and may improve the treatment capacity.

\section{Acknowledgements}

This study was financed in part by the Coordenação de Aperfeiçoamento de Pessoal de Nível Superior (CAPES), Brazil (Finance Code 001) and by the LIFE ULISES project funded by the European Union under the LIFE Financial Programme Grant Agreement No. LIFE18 ENV/ES/000165. The authors also acknowledge iESSS (ESSS Institute for Education, Research and Development) for providing the software license to run ANSYS CFD package.

\section{Nomenclature}

\begin{tabular}{|c|l|}
\hline$A$ & Area of the Raceway Pond Reactor $\left[\mathrm{m}^{2}\right]$ \\
\hline$A_{\text {paddle-wheel }}$ & Area of the paddle wheel $\left[\mathrm{m}^{2}\right]$ \\
\hline$c$ & Speed of light $\left[\mathrm{m} \mathrm{s}^{-1}\right]$ \\
\hline$d$ & Liquid depth $[\mathrm{m}]$ \\
\hline$C$ & Concentration $[\mathrm{M}]$ \\
\hline$C o V$ & Coefficient of variation \\
\hline
\end{tabular}




\begin{tabular}{|c|c|}
\hline$C_{D}$ & Drag coefficient \\
\hline$C_{T}$ & Thrust coefficient \\
\hline$D_{k, m}$ & Mass diffusivity of specie $k$ in the mixture $\left[\mathrm{m}^{2} \mathrm{~s}^{-1}\right]$ \\
\hline$D_{k}$ & Dissipation of $k$ due to turbulence $\left[\mathrm{kg} \mathrm{m}^{-1} \mathrm{~s}^{-3}\right]$ \\
\hline$D_{\omega}$ & Dissipation of $\omega$ due to turbulence $\left[\mathrm{kg} \mathrm{m}^{-3} \mathrm{~s}^{-2}\right]$ \\
\hline$E(\theta)$ & Dimensionless residence time curve function \\
\hline$E_{p, o}$ & Solar irradiance $\left[\mathrm{W} \mathrm{m}^{-2}\right]$ \\
\hline$F_{\text {Net }}$ & Net force $[\mathrm{N}]$ \\
\hline$h$ & Planck constant $\left[\mathrm{kg} \mathrm{m}^{2} \mathrm{~s}^{-1}\right]$ \\
\hline$g$ & Gravity $\left[\mathrm{m} \mathrm{s}^{-2}\right]$ \\
\hline$G_{b}$ & Generation of $k$ due to buoyance terms $\left[\mathrm{kg} \mathrm{m}^{-1} \mathrm{~s}^{-3}\right]$ \\
\hline$G_{k}$ & Generation of $k$ due to mean velocity gradients $\left[\mathrm{kg} \mathrm{m}^{-1} \mathrm{~s}^{-3}\right]$ \\
\hline$G_{\omega}$ & Generation of $\omega\left[\mathrm{kg} \mathrm{m}^{-3} \mathrm{~s}^{-2}\right]$ \\
\hline$G_{\omega b}$ & Generation of $\omega$ due to the buoyance terms $\left[\mathrm{kg} \mathrm{m}^{-3} \mathrm{~s}^{-2}\right]$ \\
\hline$I$ & Radiation intensity $\left[\mathrm{W} \mathrm{m}^{-2} \mathrm{sr}^{-1}\right]$ \\
\hline$I_{T}$ & Turbulence intensity \\
\hline$k$ & Turbulent kinetic energy $\left[\mathrm{m}^{2} \mathrm{~s}^{-2}\right]$ \\
\hline$k_{\text {app }}$ & Apparent kinetic constant $\left[\mathrm{s}^{-1}\right]$ \\
\hline$L V R P A_{k}$ & Local volumetric rate of photon absorption $\left[\mathrm{E} \mathrm{L}^{-1} \mathrm{~s}^{-1}\right]$ \\
\hline$L_{\text {axis }}$ & Distance between the paddle axis and bottom of the RPR [m] \\
\hline$L_{s-d}$ & Length of the source domain $[\mathrm{m}]$ \\
\hline$L_{\text {reactor }}$ & Length of the reactor $[\mathrm{m}]$ \\
\hline$M_{w, k}$ & Molecular weight of specie $k\left[\mathrm{~g} \mathrm{gmol}^{-1}\right]$ \\
\hline$N$ & Rotational speed of the paddle wheel $[\mathrm{rpm}]$ \\
\hline
\end{tabular}




\begin{tabular}{|c|c|}
\hline$N_{A}$ & Avogadro constant $\left[\mathrm{gmol}^{-1}\right]$ \\
\hline$N_{r}$ & Number of chemical reactions \\
\hline$N_{s}$ & Number of chemical species \\
\hline$p$ & Pressure $[\mathrm{Pa}]$ \\
\hline$P_{h}$ & Hydraulic power [W] \\
\hline$Q$ & Flow rate $\left[\mathrm{m}^{3} \mathrm{~s}^{-1}\right]$ \\
\hline$Q_{p}$ & Pumping flow rate $\left[\mathrm{m}^{3} \mathrm{~s}^{-1}\right]$ \\
\hline$r$ & Position vector $[\mathrm{m}]$ \\
\hline$s$ & Direction vector $[\mathrm{m}]$ \\
\hline$r_{l}$ & Reaction rate of reaction $l\left[\mathrm{~mol} \mathrm{~m}^{-3} \mathrm{~s}^{-1}\right]$ \\
\hline$r_{\text {paddle-wheel }}$ & Radius of the paddle wheel [m] \\
\hline$r_{t}$ & Mean radius of the paddle wheel $[\mathrm{m}]$ \\
\hline$R_{\text {bend }}$ & Radius of the bend $[\mathrm{m}]$ \\
\hline$R_{\text {deflector }}$ & Radius of the deflector at the bend $[\mathrm{m}]$ \\
\hline$S c_{t}$ & Turbulent Schmidt number \\
\hline$S_{k}$ & User-defined source terms of $k\left[\mathrm{~kg} \mathrm{~m}^{-1} \mathrm{~s}^{-3}\right]$ \\
\hline$S_{m}$ & User-defined momentum source $\left[\mathrm{kg} \mathrm{m}^{-2} \mathrm{~s}^{-2}\right]$ \\
\hline$S_{\omega}$ & User-defined source terms of $\omega\left[\mathrm{kg} \mathrm{m}^{-3} \mathrm{~s}^{-2}\right]$ \\
\hline$t$ & Time $[\mathrm{s}]$ \\
\hline$T C$ & Treatment capacity $\left[\mathrm{m} \mathrm{s}^{-1}\right]$ \\
\hline $\boldsymbol{u}$ & Velocity $\left[\mathrm{m} \mathrm{s}^{-1}\right]$ \\
\hline$V$ & Volume $\left[\mathrm{m}^{3}\right]$ \\
\hline$V_{R}$ & Volume of the reactor $\left[\mathrm{m}^{3}\right]$ \\
\hline$W_{\text {paddle-wheel }}$ & Paddle wheel width [m] \\
\hline
\end{tabular}




\begin{tabular}{|c|c|}
\hline$W_{\text {reactor }}$ & Width of the reactor $[\mathrm{m}]$ \\
\hline$x$ & Position vector $[\mathrm{m}]$ \\
\hline$x, y, z$ & Cartesian coordinates \\
\hline$Y_{k}$ & Mass fraction of specie $k$ \\
\hline \multicolumn{2}{|c|}{ Greek letters } \\
\hline$\alpha_{g}$ & Air volume fraction \\
\hline$\alpha^{*}$ & SST model parameter \\
\hline$\delta_{j i}$ & Kronecker delta \\
\hline$\theta$ & Dimensionless time \\
\hline$\theta_{\text {res }}$ & Fluid residence time $[\mathrm{s}]$ \\
\hline$\theta_{0.5}$ & Half-life time $[\mathrm{s}]$ \\
\hline$\theta_{m}$ & Mixing time $[\mathrm{s}]$ \\
\hline$\kappa$ & Radiation absorption coefficient in $\left[\mathrm{m}^{-1}\right]$ \\
\hline$\kappa_{k}^{*}$ & $\begin{array}{l}\text { Spectral-averaged molar napierian absorption coefficient for specie } k\left[\mathrm{M}^{-}\right. \\
\left.{ }^{1} \mathrm{~m}^{-1}\right]\end{array}$ \\
\hline$\lambda$ & Wavelength [m] \\
\hline$\mu$ & Viscosity [Pa s] \\
\hline$\mu_{g}$ & Viscosity of the air [Pa s] \\
\hline$\mu_{l}$ & Viscosity of the liquid [Pa s] \\
\hline$\mu_{t}$ & Turbulent viscosity [Pa s] \\
\hline$v_{k, l}^{\prime}$ & Stoichiometric coefficient for reactant $k$ in reaction $l$ \\
\hline$v_{k, l}^{\prime \prime}$ & Stoichiometric coefficient for product $k$ in reaction $l$ \\
\hline$\rho$ & Density $\left[\mathrm{kg} \mathrm{m}^{-3}\right]$ \\
\hline$\rho_{g}$ & Density of the air $\left[\mathrm{kg} \mathrm{m}^{-3}\right]$ \\
\hline
\end{tabular}




\begin{tabular}{|c|l|}
\hline$\rho_{l}$ & Density of the liquid $\left[\mathrm{kg} \mathrm{m}^{-3}\right]$ \\
\hline$\sigma$ & Standard deviation \\
\hline$\sigma_{k}$ & Turbulent Prandtl numbers for $k$ \\
\hline$\sigma_{\omega}$ & Turbulent Prandtl numbers for $\omega$ \\
\hline$\tau$ & Optical thickness \\
\hline$\tau_{j i}^{e f f}$ & Effective stress tensor $\left[\mathrm{kg} \mathrm{m}^{-2} \mathrm{~s}^{-2}\right]$ \\
\hline$\tau_{j i}$ & Viscous stress tensor $\left[\mathrm{kg} \mathrm{m}^{-2} \mathrm{~s}^{-2}\right]$ \\
\hline$\tau_{j i}^{t}$ & Turbulent stress tensor $\left[\mathrm{kg} \mathrm{m}^{-2} \mathrm{~s}^{-2}\right]$ \\
\hline$\phi_{k}$ & Quantum yield for specie $k\left[\mathrm{~mol} \mathrm{E}^{-1}\right]$ \\
\hline$\omega$ & Specific turbulence dissipation rate $\left[\mathrm{s}^{-1}\right]$ \\
\hline
\end{tabular}




\section{References}

[1] R.A. Maltos, R.W. Holloway, T.Y. Cath. Enhancement of activated sludge wastewater treatment with hydraulic selection. Sep. Purif. Technol. 250 (2020) 1383-5866. https://doi.org/10.1016/j.seppur.2020.117214.

[2] J.C. Sousa, A.R. Ribeiro, M.O. Barbosa, C. Ribeiro, M.E. Tiritan, M.F.R. Pereira, A.M.T. Silva. Monitoring of the 17 EU watch list contaminants of emerging concern in the Ave and the Sousa Rivers. Sci. Total Environ. 649 (2019) 1083-1095. https://doi.org/10.1016/j.scitotenv.2018.08.309.

[3] J.Wang, Z.Tian, Y.Huo, M.Yang, X.Zheng, Y. Zhang. Monitoring of 943 organic micropollutants in wastewater from municipal wastewater treatment plants with secondary and advanced treatment processes. J. Environ. Sci. 67 (2018) 309-317. https://doi.org/10.1016/j.jes.2017.09.014.

[4] Z. Shu, A. Singh, N. Klamerth, K. McPhedran, J.R. Bolton, M. Belosevic, M.G. El-Din. Pilot-scale $\mathrm{UV} / \mathrm{H}_{2} \mathrm{O}_{2}$ advanced oxidation process for municipal reuse water: Assessing micropollutant degradation and estrogenic impacts on goldfish (Carassius auratus L.). Water Res. 101 (2016) 157-166. https://doi.org/10.1016/j.watres.2016.05.079.

A.M. Voigt, N. Zacharias, C. Timm, F. Wasser, E. Sib, D. Skutlarek, M. Parcina, R.M. Schmithausen, T. Schwartz, N. Hembach, A. Tiehm, C. Stange, S. Engelhart, G. Bierbaum, T. Kistemann, M. Exner, H.A. Faerber, C. Schreiber. Association between antibiotic residues, antibiotic resistant bacteria and antibiotic resistance genes in anthropogenic wastewater - An evaluation of 
clinical

influences.

Chemosphere

https://doi.org/10.1016/j.chemosphere.2019.125032.

X.C. Wang. A review on the occurrence of micropollutants in the aquatic environment and their fate and removal during wastewater treatment. Sci. Total Environ.

$473-474$

619-641. https://doi.org/10.1016/j.scitotenv.2013.12.065. on the use of chelating agents as an alternative to promote photo-Fenton at neutral pH: Current trends, knowledge gap and future studies. Sci. Total Environ. 710 (2020). https://doi.org/10.1016/j.scitotenv.2019.134872. J.L. Casas López, P. Plaza-Bolaños. Neutral or acidic pH for the removal of contaminants of emerging concern in wastewater by solar photo-Fenton? A techno-economic assessment of continuous raceway pond reactors. Sci. Total Environ. 736 (2020). https://doi.org/10.1016/j.scitotenv.2020.139681.

[9] N. Seraghni, B. Dekkiche, S. Belattar, N. Debbache, T. Sehili. Role of Fe(III) and oxalic acid in the photo-Fenton system for 3-Methylphenol degradation in aqueous solution under natural and artificial light. Int. J. Chem. React. Eng. 16 (2018). https://doi.org/10.1515/ijcre-2017-0211. M.R.A. Silva, A.G. Trovó, R.F.P. Nogueira. Degradation of the herbicide tebuthiuron using solar photo-Fenton process and ferric citrate complex at circumneutral pH. J. Photochem. Photobiol. A 191 (2007) 187-192. https://doi.org/10.1016/j.jphotochem.2007.04.022. 
Tiburtius, J. Argüello, C. Sirtori. Solar photo-Fenton-like process at neutral pH: Fe(III)-EDDS complex formation and optimization of experimental conditions for degradation of pharmaceuticals. Catal. Today 328 (2019) 259-266. https://doi.org/10.1016/j.cattod.2019.01.006.

A. de Luca, R. Dantas, S. Esplugas. Study of Fe(III)-NTA chelates stability for applicability in photo-Fenton at neutral pH. Appl. Catal. B 179 (2015) 372-379. https://doi.org/10.1016/j.apcatb.2015.05.025.

N. López-Vinent, A. Cruz-Alcalde, J.A. Malvestiti, P. Marco, J. Giménez, S. Esplugas. Organic fertilizer as a chelating agent in photo-Fenton at neutral $\mathrm{pH}$ with LEDs for agricultural wastewater reuse: Micropollutant abatement and bacterial inactivation. Chem. Eng. J. 388 (2020). https://doi.org/10.1016/j.cej.2020.124246.

[14] S. Nahim-Granados, I. Oller, S. Malato, J.A. Sánchez Pérez, M.I. PoloLopez. Commercial fertilizer as effective iron chelate $\left(\mathrm{Fe}^{3+}\right.$-EDDHA) for wastewater disinfection under natural sunlight for reusing in irrigation. Appl. Catal. B 253 (2019) 286-292. https://doi.org/10.1016/j.apcatb.2019.04.041. P. Soriano-Molina, J.L. García Sánchez, S. Malato, L.A. Pérez-Estrada, J.A. Sánchez Pérez. Effect of volumetric rate of photon absorption on the kinetics of micropollutant removal by solar photo-Fenton with $\mathrm{Fe}^{3+}$-EDDS at neutral $\mathrm{pH}$. Chem. Eng. J. 331 (2018) 84-92. https://doi.org/10.1016/j.cej.2017.08.096. S. Miralles-Cuevas, F. Audino, I. Oller, R. Sánchez-Moreno, J.A. Sánchez Pérez, S. Malato. Pharmaceuticals removal from natural water by nanofiltration combined with advanced tertiary treatments (solar photo-Fenton, photo-Fenton- 
like Fe(III)-EDDS complex and ozonation). Sep. Purif. Technol. 122 (2014) 515522. https://doi.org/10.1016/j.seppur.2013.12.006.

Malato, J.A. Sánchez Pérez. Mechanistic modeling of solar photo-Fenton process with $\mathrm{Fe}^{3+}$-EDDS at neutral pH. Appl. Catal. B 233 (2018) 234-242. https://doi.org/10.1016/j.apcatb.2018.04.005.

Pérez. New approach to solar photo-Fenton operation. Raceway ponds as tertiary treatment technology. J. Hazard. Mater. 279 (2014) 322-329. https://doi.org/10.1016/j.jhazmat.2014.07.010. P. Soriano-Molina, J.L. García Sánchez, S. Malato, P. Plaza-Bolañosa, A. Agüera, J. A. Sánchez Pérez. On the design and operation of solar photo-Fenton open reactors for the removal of contaminants of emerging concern from WWTP effluents at neutral pH. Appl. Catal. B $256 \quad$ (2019). https://doi.org/10.1016/j.apcatb.2019.117801.

[20] P. Soriano-Molina, P. Plaza-Bolaños, A. Lorenzo, A. Agüera, J.L. García Sánchez, S. Malato, J.A. Sánchez Pérez. Assessment of solar raceway pond reactors for removal of contaminants of emerging concern by photo-Fenton at circumneutral $\mathrm{pH}$ from very different municipal wastewater effluents. Chem. Eng. J. 366 (2019) 141-149. https://doi.org/10.1016/j.cej.2019.02.074. S. Arzate, M.C. Campos-Mañas, S. Miralles-Cuevas, A. Agüera, J.L. García Sánchez, J.A. Sánchez Pérez. Removal of contaminants of emerging concern by continuous flow solar photo-Fenton process at neutral $\mathrm{pH}$ in open 
$\begin{array}{lllll}\text { reactors. } & \text { J. } & \text { Environ. } & \text { Manage. } & 261\end{array}$ https://doi.org/10.1016/j.jenvman.2020.110265.

[22] A. Kusmayadi, G.P. Philippidis, H-W. Yen. Application of computational fluid dynamics to raceways combining paddlewheel and $\mathrm{CO}_{2}$ spargers to enhance microalgae growth. J. Biosci. Bioeng. 129 (2020) 93-98. https://doi.org/10.1016/j.jbiosc.2019.06.013.

[23] Z. Chen, X. Zhang, Z. Jiang, X. Chen, H. He, X. Zhang. Light/dark cycle of microalgae cells in raceway ponds: Effects of paddlewheel rotational speeds and baffles installation. Bioresour. Technol. 219 (2016) 387-391. https://doi.org/10.1016/j.biortech.2016.07.108.

[24] S.S. Sawant, S.N. Gosavi, H.P. Khadamkar, C.S. Mathpati, R. Pandit, A.M. Lali. Energy efficient design of high depth raceway pond using computational fluid dynamics. Renew. Energy 133 (2019) 528-537. https://doi.org/10.1016/j.renene.2018.10.016.

[25] G. Rivas, I. Carra, J.L. García Sánchez, J.L. Casas López, S. Malato, J.A. Sánchez Pérez. Modelling of the operation of raceway pond reactors for micropollutant removal by solar photo-Fenton as a function of photon absorption. Appl. Catal. B 178 (2015) 210-217. https://doi.org/10.1016/j.apcatb.2014.09.015.

[26] R. Hreiz, B. Sialve, J. Morchain, R. Escudié, J-P. Steyer, P. Guiraud. Experimental and numerical investigation of hydrodynamics in raceway reactors used for algaculture. Chem. Eng. J. $250 \quad$ (2014) 230-239. https://doi.org/10.1016/j.cej.2014.03.027.

[27] J. Huang, Q. Yang, J. Chen, M. Wan, J. Ying, F. Fan, J. Wang, W. Li, Y. Li. Design and optimization of a novel airlift-driven sloping raceway pond with 
numerical and practical experiments. Algal Res. 20 (2016) 164-171. https://doi.org/10.1016/j.algal.2016.09.023.

[28] F.R. Menter. Two-equation eddy-viscosity turbulence models for engineering applications. AIAA J. $32 \quad$ (1994) 1598-1605. https://doi.org/10.2514/3.12149.

[29] ANSYS, ANSYS Documentation. https://ansyshelp.ansys.com/. (June accessed 2020).

[30] T. Pirasaci, A.Y. Manisali, I. Dogaris, G. Philippidis, A.K. Sunol. Hydrodynamic design of an enclosed Horizontal BioReactor (HBR) for algae $\begin{array}{lllll}\text { cultivation. } & \text { Algal } & \text { Res. } & 28 & \text { (2017) }\end{array}$ https://doi.org/10.1016/j.algal.2017.10.009.

[31] V.T. Nguyen, S.S. Guillou, J. Thiebot, A. Santa-Cruz. Modelling turbulence with an Actuator Disk representing a tidal turbine. Renew. Energy 97 (2016) 625-635. https://doi.org/10.1016/j.renene.2016.06.014.

[32] C. Haringa, R. Vandewijer, R.F. Mudde. Inter-compartment interaction in multi-impeller mixing. Part II. Experiments, sliding mesh and large eddy simulations. Chem. Eng. Res. Des. $136 \quad$ (2018) 886-899. https://doi.org/10.1016/j.cherd.2018.06.007. E. B. Nauman. Chemical Reactor Design, Optimization and Scaleup, New York: McGraw-Hill, 2002.

[34] G. Li Puma. Modeling of thin-film slurry photocatalytic reactors affected by radiation scattering. Environ. Sci. Technol. 37 (2003) 5783-5791. https://doi.org/10.1021/es0300362. 